\title{
Interplay between mesenchymal stromal cells and immune system: clinical applications in immune-related diseases
}

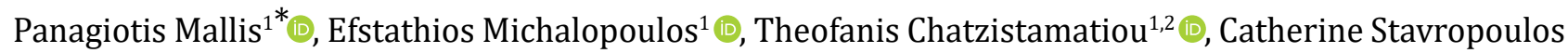 \\ Giokas $^{1}$ (D) \\ ${ }^{1}$ Hellenic Cord Blood Bank, Biomedical Research Foundation Academy of Athens, 11527 Athens, Greece \\ ${ }^{2}$ Histocompatibility \& Immunogenetics Lab, Hellenic Cord Blood Bank, Biomedical Research Foundation Academy of Athens, \\ 11527 Athens, Greece
}

*Correspondence: Panagiotis Mallis, Hellenic Cord Blood Bank, Biomedical Research Foundation Academy of Athens, 4 Soranou Effesiou Street, 11527 Athens, Greece. pmallis@bioacademy.gr

Academic Editor: Dominique J Charron, Hôpital Saint-Louis, France; Reem Al-Daccak, Hôpital Saint-Louis, France

Received: April 7, 2021 Accepted: June 7, 2021 Published: June 30, 2021

Cite this article: Mallis P, Michalopoulos E, Chatzistamatiou T, Giokas CS. Interplay between mesenchymal stromal cells and immune system: clinical applications in immune-related diseases. Explor Immunol. 2021;1:112-39. https://doi.org/10.37349/ ei.2021.00010

\begin{abstract}
Mesenchymal stromal cells (MSCs) are a mesodermal stem cell population, with known self-renewal and multilineage differentiation properties. In the last century, MSCs have been widely used in regenerative medicine and tissue engineering approaches. MSCs initially were isolated from bone marrow aspirates, but currently have been identified in a great number of tissues of the human body. Besides their utilization in regenerative medicine, MSCs possess significant immunoregulatory/immunosuppressive properties, through interaction with the cells of innate and adaptive immunity. MSCs can exert their immunomodulatory properties with either cell-cell contact or via paracrine secretion of molecules, such as cytokines, growth factors and chemokines. Of particular importance, the MSCs' immunomodulatory properties are explored as promising therapeutic strategies in immune-related disorders, such as autoimmune diseases, graft versus host disease, cancer. MSCs may also have an additional impact on coronavirus disease-19 (COVID-19), by attenuating the severe symptoms of this disorder. Nowadays, a great number of clinical trials, of MSC-mediated therapies are evaluated for their therapeutic potential. In this review, the current knowledge on cellular and molecular mechanisms involved in MSC-mediated immunomodulation were highlighted. Also, the most important aspects, regarding their potential application in immune-related diseases, will be highlighted. The broad application of MSCs has emerged their role as key immunomodulatory players, therefore their utilization in many disease situations is full of possibilities for future clinical treatment.
\end{abstract}

\section{Keywords}

Mesenchymal stromal cells, immunomodulation, adaptive immunity, graft versus host disease, autoimmune disorders, COVID-19 


\section{Introduction}

The mesenchymal stromal cells (MSCs) have been widely studied over the past 30 years for their interesting properties and their clinical potential in disease administration [1]. In addition, MSCs due to their differentiation capabilities and novel stem cell properties could represent a valuable cell source, that can be used in the rapidly growing field of regenerative medicine [1]. MSCs compromise a mesodermal multipotent cellular population, which can be derived from a great number of tissue sources $[1,2]$. Initially, MSCs were isolated from bone marrow (BM) aspirates [3]. Except for BM, well-defined MSCs can be isolated from Wharton's Jelly (WJ) tissue, placenta, adipose tissue (AT), amniotic fluid, dental pulp, stromal vascular fraction and umbilical cord blood (UCB) [4, 5]. However, distinct variations, regarding the proliferation potential, stemness, secretome and transcription profile, may exist between MSCs from different sources [6-8]. A great body of research evidence has indicated that fetal MSCs may have greater proliferation potential due to longer telomeres and increased telomerase activity and also may exert better immunoregulatory properties compared to adult MSCs [6-8]. Additionally, fetal MSCs are bearing less mutagenic and epigenetic changes in their genome, therefore may be characterized by greater genome stability compared to the adult stem cell populations [6-8]. The International Society for Cell and Gene Therapy (ISCT) in 2006, proposed the minimum criteria for defining the MSC population [9]. The criteria of ISCT to properly define the MSCs include:

1. Spindle-shaped plastic adherent cells;

2. Expression of specific surface antigens (clusters of differentiation-CDs). Specifically, positive expression ( $\geq 95 \%$ ) of CD73, CD90, CD105, and low expression ( $\leq 3 \%$ ) of CD34, CD45, CD11a, CD19 and human leukocyte antigen-death receptor (HLA-DR);

3. Mesodermal multilineage differentiation towards "osteocytes", "adipocytes" and "chondrocytes".

In 2019, the ISCT"s MSC committee reported that "Mesenchymal Stromal Cells" have specific secretory, immunomodulatory, and homing properties and are distinguished from "Mesenchymal Stem Cells", which are characterized by restricted properties focused on self-renewal and differentiation potential [10]. For Caplan, the acronym MSC stands for "medicinal signaling cells", indicating that the main attribute of MSC therapy is the secretion of bioactive molecules, cytokines, growth factors, and chemokines [11, 12]. Caplan also mentioned that MSCs play a critical role in the activation, maturation, proliferation, and differentiation among the cells which link innate to adaptive immunity [11,12]. Friedenstein was the first person to describe the isolation of clonogenic, proliferating fibroblastic MSCs from rat BM [13]. He showed that colony-forming unit-fibroblasts (CFU-Fs) derived stromal cells can serve as feeder layers for the culture of hematopoietic stem cells (HSCs) and have differentiation potential towards "osteocytes", "chondrocytes" and "adipocytes" [14]. Although BM-MSCs have been widely used in clinical studies, the adipose and umbilical cord (UC) tissues may compromise more attractive sources. Specifically, MSCs represent $0.01-0.001 \%$ of total nucleated cells in BM [15]. On the other hand, it is speculated that $1-10 \%$ of the resident cells in AT, are MSCs [16]. Unlike the previously described sources, MSCs can be non-invasively isolated from UCB, WJ tissue, which are discarded after gestation.

MSCs, isolated from different sources, express specific surface antigen molecules dependent on the tissue origin [17]. For example, the surface markers of MSCs isolated from the lung are distinct from those that are derived from the BM [17]. Key specific markers for the selective identification and isolation of MSCs are still under investigation.

MSC-mediated immunomodulation operates through a synergy of cell contact mechanisms and the secretion of soluble factors $[18,19]$. The weak expression of major histocompatibility complex (MHC) class I protects MSCs from natural killer (NK) cell-mediated clearance. In addition, the lack of the membrane-bound MHC class II from MSCs is related to reduced allorecognition by CD4+ T cells [17]. The unique properties of MSCs, including the hemopoietic support, tissue healing and immunomodulation, make them candidate cellular populations, in order to be used as a novel therapy, for the proper administration of many disorders [20, 21].

Taking into consideration the above information, the current review will highlight the immunomodulatory properties of MSCs. Furthermore, the clinical application of MSCs in immune-related disorders will be 
comprehensively discussed, by outlining the most recent clinical trials, where MSCs are used as potential stem cell therapy.

\section{The interplay between MSCs and immune system}

MSCs can act positively in homeostasis by modulating immune responses. Specifically, MSCs can migrate to the inflamed tissues, through the circulation. Upon tissue injury, MSCs migrate through a gradient chemokinedependent manner [CXCL12 and stromal derived factor-1 (SDF-1)]. In this way, MSCs upregulate the CD44 and $\alpha v \beta 1$ integrin, interact with P/E selectins, vascular cell adhesion molecule-1 (VCAM-1) and intracellular adhesion molecule-1 (ICAM-1), and perform the rolling adhesion to the endothelium surface of the blood vessel until reaching the injury site [18-20]. Transendothelial migration of MSCs is performed, in a process mediated by junctional adhesion molecules (JAMs), platelet-endothelial cell adhesion molecule-1 (PECAM-1) and cadherins [18-20]. Through there, MSCs can modulate the proliferation, differentiation and activity of the majority of the immune cells, such as T cells, B cells, NK cells, dendritic cells, macrophages, etc., in a direct or indirect dependent manner (Figure 1) [18-20]. MSCs could inhibit proliferation and activation of T cells and induce differentiation and expansion of regulatory T cells [22]. It has been shown, that BM-MSCs could suppress delayed-type hypersensitivity and graft versus host disease (GvHD) due to the production of nitric oxide (NO) and interferon- $\gamma$ (IFN- $\gamma$ ). Also, MSCs exert their immunoregulatory function with the production of other soluble factors such as indoleamine 2,3 dioxygenase (IDO), hepatocyte growth factor (HGF), transforming growth factor- $\beta 1$ (TGF- $\beta 1$ ), and anti-inflammatory cytokines [interleukin (IL)-1RA, IL10, IL-13, etc., Table 1] [11]. They can induce differentiation of CD34+ HSCs to regulatory dendritic cells (DCs) and induced expansion of regulatory T cells. Also, the HLA-G and its isoforms (HLA-G1-G7) act as immunosuppressive mediators of human MSCs derived from BM, AT and WJ tissue [11,12]. MSCs can act both in immune activation and immune suppression, depending on the microenvironment stimuli [22-24]. This activity is also known as the function of the "sensor" and "switcher" of the immune system. The significant immunoregulatory/ immunosuppressive properties of MSCs have been exploited for therapeutic applications, including HSC transplantation (HSCT), GvHD, autoimmune disorders and recently in coronavirus disease-19 (COVID-19).

\section{MSCs and innate immunity}

\section{Interaction between MSCs and monocytes}

Monocytes are representing $10 \%$ of the circulating leukocytes in the peripheral blood. Monocytes are derived from HSCs and especially from myeloid precursors, which can further differentiate between M1 and M2 macrophages and DCs [25]. Based on their CDs expression, monocytes are categorized into 3 subsets: the classical monocytes (CD14+, CD16-), minor monocytes subsets (CD14++, CD16+) and the pro-inflammatory monocytes (CD14+, CD16+) [26]. Dependent to microenvironment stimuli, monocytes can express several additional CDs, such as those that are related to the M1 macrophage phenotype (CD115+, CD11b+, Ly6C+, CCR2+, CXC3CR1+) or with M2 macrophage phenotype (CD115+, CD11b+, Ly6C-, CCR2-, CXC3CR1+). Evidence from research and clinical data has shown that BM-MSCs can be mobilized and promote the movement of monocytes from the BM to peripheral blood, upon microbial pathogen detection [25, 26]. MSCs can regulate the monocytes' function, through the secretion of HGF and prostaglandin-E2 (PGE2). In this way, HGF and PGE2 mediated immunomodulation can lead to monocyte differentiation into M2 macrophages, promoting anti-inflammatory cytokine production and wound repair [27, 28]. Moreover, Min et al. [29], showed that UC-MSCs can regulate the monocyte functions through a direct-dependent manner. In this study, it was shown that UC-MSCs can communicate with monocytes through developed tunneling nanotubes (TNTs) [29]. TNTs represent cellular extensions that can be used for the transfer of various cytosolic mediators such as proteins and RNAs, between the "connected" cells. Moreover, in the same study was presented that lowdensity lipoprotein receptor-relate proteins (LRP) 1,11 and 12 play a significant role in the formation of TNTs between UC-MSCs and monocytes [29]. In this way, MSCs can either enhance the phagocytotic activity of M1 macrophages or can promote the switching to the M2 macrophage phenotype. 
A)

Intravenous Infusion of MSCs

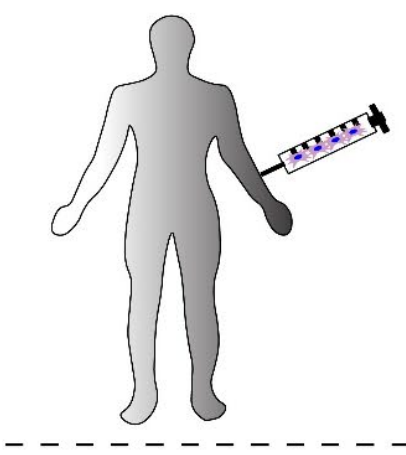

Migration of MSCs in a gradient chemokine dependent manner

C)

Immunomodulatory Properties of MSCs
B)

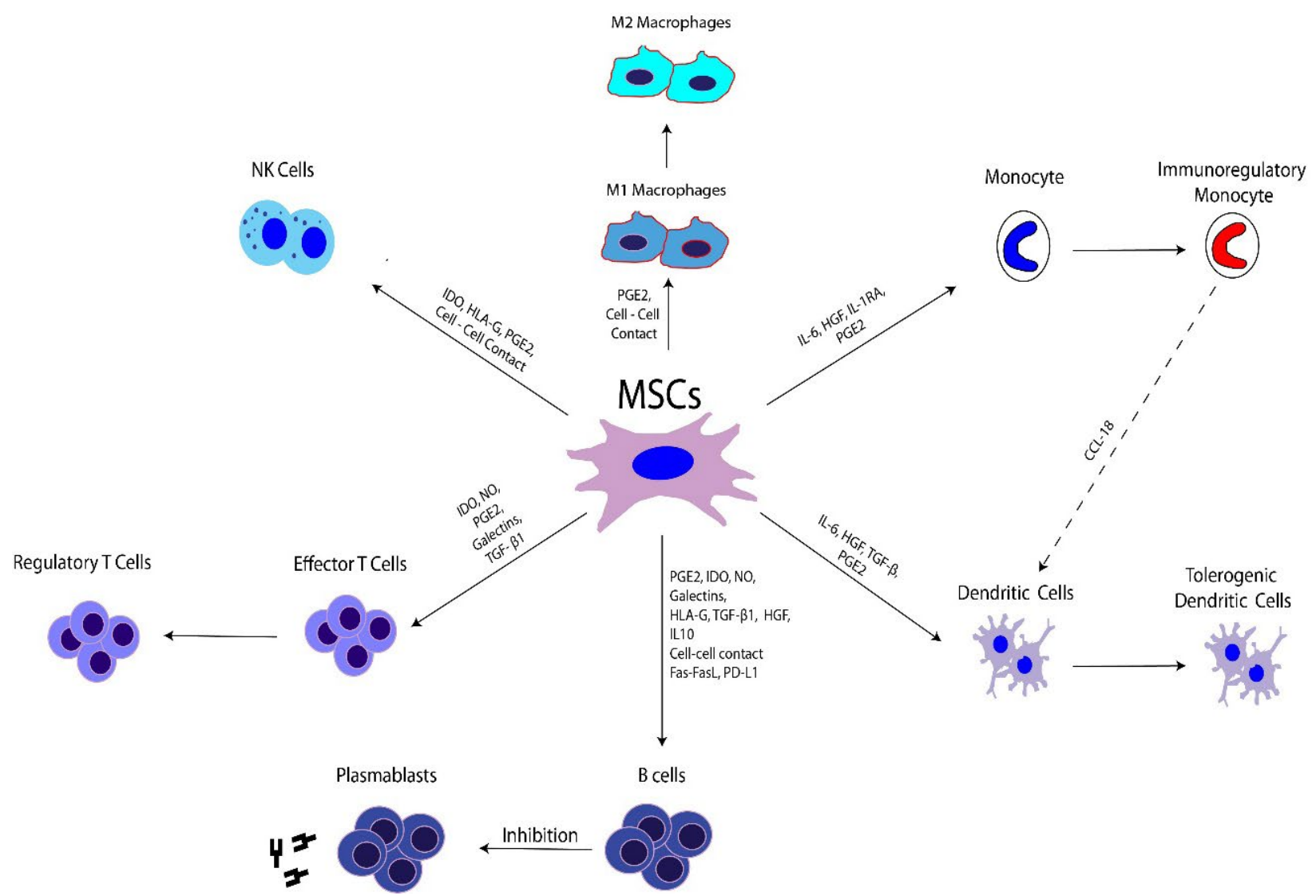

Figure 1. The interplay between MSCs and immune Cells. A) MSCs are intravenously infused into the patient; B) MSCs can migrate to the site of inflammation. Chemokine production (CXCL12, SDF-1) is performed from the damaged tissue. Indeed, damaged epithelial or endothelial cells can produce high amounts of chemokine any inflammatory cytokines, in order to mobilize the immune cells. Migration of MSCs is performed through a gradient chemokine-dependent manner; C) MSCs can modulate immune responses through either cell-cell interactions or via the production of soluble factors. Target cells of the immunomodulationexerted by MSCs are the macrophages, dendritic cells, NK cells, T and B cells 
Table 1. Immunomodulation mechanisms of MSCs. MSCs modulate the immune responses of the target immune cells, using cell-cell interactions and the secretion of soluble molecules

\begin{tabular}{|c|c|c|c|c|}
\hline $\begin{array}{l}\text { Immunoregulatory } \\
\text { mediators }\end{array}$ & Interactions & Target immune cells & Result & Refs \\
\hline Fas/Fas ligand & Cell-cell contact & Macrophages, mDCs, T and B cells & Apoptosis & [34] \\
\hline TNF- $\alpha / T N F-R$ & Cell-cell contact & Macrophages, mDCs, $\mathrm{T}$ and $\mathrm{B}$ cells & Apoptosis & [38] \\
\hline PD-L1/PD-1 & Cell-cell contact & $T$ and $B$ cells & Inhibition of cellular proliferation & {$[66]$} \\
\hline $\begin{array}{l}\text { HLA-G/LIRB2 (ILT4/ } \\
\text { CD85d) and KIR2DL4 } \\
\text { (CD158d) }\end{array}$ & Cell-cell contact & mDCs, NK cells and T cells & Inhibition of cellular proliferation & {$[32,75]$} \\
\hline \multirow[t]{2}{*}{ PGE2 } & Soluble factors & Macrophages, mDCs, $\mathrm{T}$ and $\mathrm{B}$ cells & M2 macrophages switching & [57] \\
\hline & & & $\begin{array}{l}\text { Inhibition of DCs maturation, } \mathrm{T} \text { and } \mathrm{B} \\
\text { cell inactivation }\end{array}$ & \\
\hline IDO & Soluble factors & mDCs NK cells, $T$ and B cells & G0/G1 cell cycle arrest & {$[34,76]$} \\
\hline NO & Soluble factors & Macrophages, $T$ and $B$ cells & Inhibition of cellular proliferation & {$[34,76]$} \\
\hline Galectins & Soluble factors & $T$ and $B$ cells & Inhibition of $\mathrm{T}$ and $\mathrm{B}$ cell proliferation & {$[76,77]$} \\
\hline $\begin{array}{l}\text { Soluble HLA-G } \\
\text { isoforms (HLA-G5-G7) }\end{array}$ & Soluble factors & mDCs, NK cells and T cells & Inhibition of cellular proliferation & {$[32,75]$} \\
\hline $\begin{array}{l}\text { miR-21-5p, miR-142- } \\
3 p, m i R-223-3 p \text {, and } \\
\text { miR-126-3p }\end{array}$ & Soluble factors & $\mathrm{mDCs}$ & Inhibition of DC maturation & $\begin{array}{l}{[21,46-} \\
50]\end{array}$ \\
\hline $\begin{array}{l}\text { miR-145, miR-146 and } \\
\text { miR-155 }\end{array}$ & Soluble factors & Macrophages, $T$ and $B$ cells & $\begin{array}{l}\text { Inactivation of M1 macrophages; } \\
\text { switching from Th1 to Th2 responses }\end{array}$ & $\begin{array}{l}{[21,46-} \\
50]\end{array}$ \\
\hline
\end{tabular}

\section{Interaction between MSCs and macrophages}

Macrophage and DCs are playing a central role in innate immunity as antigen-presenting cells (APCs), leading to antigen-specific $\mathrm{T}$ and $\mathrm{B}$ cell activation. Monocytes in response to inflammatory stimuli are differentiating into either M1 or M2 macrophages [30, 31]. It has been shown that MSCs are co-working with innate immune cells. Moreover, MSCs, located in the BM, can regulate the HSCs differentiation in a homeostatic manner, resulting in the release of innate immunity cells to the peripheral circulation. In this way, macrophages correspond efficiently to the microbial challenge [30,31]. MSCs, dependent on microenvironment stimuli, effectively can regulate the macrophage phenotype polarization. In the initial stage of macrophage-mediated antigen presentation, the produced IFN- $\gamma$ can stimulate the MSCs to produce tumor necrosis factor- $\alpha$ (TNF- $\alpha$ ), monocyte chemoattractant protein-1 (MCP-1) and IL-1 $\beta$ [32]. This cytokine combination can further promote the M1 macrophage phenotype adaptation. M1 macrophages are responsible for the presentation of antigen epitopes to DCs, in a process where inflammatory cytokines, including TNF- $\alpha$, IL- $1 \alpha / \beta$, IL- 6 and IL-12, are produced [33]. This set of inflammatory cytokines in combination with the antigen presentation process can promote the Th1 responses.

MSCs have been shown also to promote the polarization of macrophages towards the anti-inflammatory M2 phenotype [34]. MSCs, through the secretion of PGE2, IL-1 receptor antagonist (IL-1Ra), IL-6 and HGF, can induce the M2 macrophage phenotype switch. M2 macrophages express high levels of IL-10 and decreased levels of IL-12p70, TNF- $\alpha$, and IL-17 [32-37]. The study of Gur-Wahnon et al. [38], showed that cell-cell interaction between MSCs and macrophages can induce the expression of the signal transducer activators of transcription-3 (STAT3) in macrophages. This event can enhance the IL-10 production by macrophages and DCs, favoring further their immunosuppressive properties. In addition, M2 macrophages are characterized by high expression of HLA class II, CD45R, and CD11b, Chemokine (C-C motif) ligand (CCL)-18 and TGF- $\beta 1$, which further can suppress the overactivated $\mathrm{T}$ cells and also can promote the differentiation of CD4+ T cells to CD4+ CD25+ Foxp3+ T regulatory cells (Tregs) [34]. Especially for CCL-18, evidence from neutralization experiments has shown a significant reduction of MSCs-mediated CD4+, CD25+, Foxp3 Treg formation. Furthermore, M2 macrophages, characterized by increased CCL-18 production, can promote the tolerogenic 
DCs phenotype. Tolerogenic DCs are strongly related to the activation of CD4+CD25+FOXP3+Tregs, regulating in this way properly the immune response (Figure 1).

\section{Interaction between MSCs and DCs}

MSCs can regulate efficiently the DC migration and maturation, through cell-cell interactions and soluble factors secretion. DCs are professional APCs, which are characterized by high expression of MHC class II and CD11c [39]. DCs are localized to all human tissues, where they represent the homeostatic "guardians". In case of homeostatic imbalance DCs, are co-worked with tissue macrophages for antigen presentation to "naïve" T cells [39]. In addition, DCs can regulate the actions of other immune cells, such as NK and innate lymphoid cells (ILCs) through cytokine and growth factors release. DCs, based on their functional state, can be distinguished into "immature" and "mature" phenotypes. Specifically, "mature" DCs (mDCs) are related with the antigen presentation to "naïve" $\mathrm{T}$ cells in order the latter to be activated and become effector T cells. The above process is performed after the communication between mDCs and "naïve" $\mathrm{T}$ cells in the secondary lymphoid organs [39].

It has been shown, that mature type 1 DCs co-cultured with MSCs, express high levels of IL-10, and are less capable to support the CD4+ T cell activation and proliferation [40]. Furthermore, lipopolisacharide (LPS)activated MSCs are capable of inducing the differentiation of mature DCs to DC regs, through the HGF/Akt signaling pathway [41-43]. Spaggiari et al. [44], showed that MSCs can exert significant inhibitory effects when these cells are presented at the early stages of DC differentiation process. Importantly, it was revealed that MSCs (even at low levels) can interfere with the DC maturation process, as was indicated by the low expression of CD80, CD83, CD86 and the secreted cytokines IL- 6 and IL-12 (by DCs). In another study conducted by Liu et al. [45], showed that the secretion of TNF- $\alpha$-stimulating gene 6 (TSG-6) by MSCs can suppress the DC maturation through the inactivation of mitogen-activated protein kinase (MAPK) and nuclear factor-kappa $B$ (NF- $\mathrm{KB}$ ) signaling pathways (Table 1). Another potent inhibitory mechanism of DC maturation, which is under investigation, is through the production of specific miRNAs, including miR-21-5p, miR-142-3p, miR-223-3p and miR-126-3p [21, 46-50]. Extracellular vesicles secreted by stimulated MSCs, are including high levels of the aforementioned microRNAs (miRs), however, more research is needed towards this field (Table 1).

\section{Interaction between MSCs and NK cells}

Nk cells are important effector cells that exert both cytotoxic and cytokine release action against microbial infection and several types of tumors. Originally, NK cells were described as large granular lymphocytes but recent research work focused on their biology, indicated that these cells are recognized as distinct lymphocyte lineage [51]. NK cells are originated from the lymphoid lineages (separate from $\mathrm{T}$ and B cell lineages) and are playing a crucial role in the innate immune response [51]. It has been reported, that MSCs are strong inhibitors of NK cell proliferation, cytotoxic activity and cytokine production [51]. NK cells are expressing the killer cell immunoglobulin-like receptors (KIRs) and also the natural cytotoxicity receptors NKp30, NKp44 and NKp46, exerting in this way their inhibitory and cytotoxic effects, respectively [52, 53]. MSCs exhibit a remarkably complex interplay with NK cells. MSCs are susceptible to cytolytic actions of NK cells, given that are characterized by low expression of HLA class I molecules [54]. However, IFN- $\gamma$ activated MSCs are characterized by high HLA class I expression, which can strongly interact with KIRs, promoting the inhibition of cytolysis mediated by NK cells [55]. MSCs can induce the immunosuppression of NK cells, utilizing mostly the soluble factors such as IDO, PGE2, TGF- $\beta 1$ and HGF [56-58]. Except for this mechanism, Toll-like receptors (TLRs), including TL3 and TLR4, which their expression is increased in activated MSCs, can lead to increased NK cell immunosuppression (Table 1) [56-58].

\section{Interaction between MSCs and the complement system}

A central component of innate immunity is the complement system. The complement system has been related to the rejection of transplanted organs and tissues and more recently with the clearance of infused MSCs from the circulation [59]. The central step for the complement activation is the cleavage of C3 into C3a and C3b [60]. Further cleavage of C3b into the surface-bound fragments iC $3 \mathrm{~b}$ and C3dg, is performed. The cleaved surfacebound fragments of $\mathrm{C} 3 \mathrm{~b}$ are becoming ligands of those cells that are expressing the complement receptors 
CR1-4. Moreover, specific convertases are recruited for the proper production of the anaphylatoxins C3a and C5a (cleaved from the complement components C3 and C5), which are found specifically in the inflamed and injured tissues $[60,61]$. In such a way, the activation of the complement cascade can provide specific stimuli cues, through the increase of the chemoattractant factors. This can result in the mobilization of immune cells, and the formation of membrane attack complexes (MAC), which are responsible for the destruction of the target pathogens. Indeed, activated neutrophils by complement components can respond against the pathogens, through the production of reactive oxygen species (ROS), neutrophil extracellular traps (NETs) and proteases secretion [61].

MSCs express the $\mathrm{C} 3 \mathrm{a}$ and $\mathrm{C} 5 \mathrm{a}$ receptors ( $\mathrm{C} 3 \mathrm{aR}$ and $\mathrm{C} 5 \mathrm{aR}$ ), and in this way can be mobilized to the inflamed tissue, through the binding of $\mathrm{C} 3$ and C5 breakdown products [62]. Moreover, the above binding can enhance the MSC resistance to ROS, produced by the immune cells. It has been also shown that C3 triggered MSCs can suppress the proliferation of peripheral blood mononuclear cells. Also, MSCs are protected from the lytic activity of complement components, through the surface expression of CD46, CD55 and CD59 [62-64]. Furthermore, it has been shown that MSCs are vulnerable to complement clearance mediated by MAC formation. A possible way to inhibit the complement actions against MSCs, is through the production of factor H. IFN- $\gamma$ stimulated MSCs can express the factor $\mathrm{H}$, which is responsible for reducing the action of $\mathrm{C} 3$ and C5 convertases. However, there is increasing evidence that infused MSCs cannot escape from the complement clearance, through the triggering of the instant-blood-mediated-inflammatory-response (IBMIR) [63]. The latter can be initiated after the interaction of infused MSCs with peripheral blood immune cells, which can activate the complement cascade. Taking into consideration the above data, a dynamic balance between MSCs and complement exist, in order either to stimulate and mobilize them towards the inflamed tissue or to generate a more sophisticated immunosuppressive environment with the immune cells.

\section{MSCs and adaptive immunity}

\section{Interaction between MSCs and T cells}

MSCs can modulate the T cell responses, utilizing both the cell-cell contact interactions and the soluble factor secretion. $\mathrm{T}$ cell apoptosis can be mediated through the direct interaction between MSCs and $\mathrm{T}$ cells [65]. It has been shown, that LPS-stimulated MSCs can express the Fas ligand, which can bind to the Fas receptor of the overactivated CD4+ T cells [65]. This in turn could result in apoptosis induction through the downstream activation of Fas-associated death domain (FADD) and caspases [65]. Another potent T cell apoptosis mechanism is through the interaction of programmed death ligand-1 (PD-L1) and programmed death-1 (PD-1). Specifically, MSCs express the PD-L1, which in turn can bind to the inhibitory checkpoint molecule PD-1, expressed in CD4+ T cells [66]. The $\mathrm{T}$ cell inhibition is mediated through the activation of Src homology 2 domain-containing protein tyrosine phosphatases (SHP)-1 and SHP-2, which can inhibit the MAPK, leading in this way to inhibition of T cell proliferation [66]. Another mechanism that MSCs are using for the T cell inhibition, is through the expression of soluble factors, such as PGE2, IDO, NO TGF- $\beta 1$ and HGF (Table 1) [67]. Specifically, PGE2 is a prostanoid, which is derived from arachidonic acid through the action of cyclooxygenase (COX)-1 and 2 and PGE synthase [68]. PGE2 is responsible for the production of cyclic adenosite monophosphate (cAMP) in activated T cells. cAMP plays a key role in the downregulation of IL-2 and IL-2R expression and abrogation of $\mathrm{Ca}^{2+}$ after $\mathrm{T}$ cell receptor (TCR) activation. Also, PGE2 negatively regulates the hydrolysis of phosphatidylinositol and the production of diacylglycerol and inositol phosphate, resulting in T cell inactivation [68]. Recently, it was reported that PGE2 may be involved in T cell polarization, promoting further Th2 responses. In addition, PGE2 produced by MSCs can orchestrate the CD4+CD25+FOXP3+ T reg responses, influencing, even more, the immunosuppression of hyperactivated $\mathrm{T}$ cells [21, 67-71]. MSCs also can express large amounts of IDO, which is a strong inhibitor of T cell proliferation [65]. IDO can effectively block the metabolism of tryptophan to kynurenine in T cells, leading to G0/G1 cycle arrest. Additionally, the synergistic effect of TGF- $\beta 1$ and HGF may influence even more the T cell apoptosis mediated by IDO involved mechanism [65]. NO is another immunosuppressive agent. Specifically, NO can downregulate the signal transducer and activator of transcription-5 (STAT-5), inhibiting in this way the TCR mediated T cell activation and inflammatory cytokine production [32]. 


\section{Interaction between MSCs and B cells}

MSCs dependent on microenvironment stimuli can modulate B cell responses [72]. Indeed, under immunological quiescent conditions, MSCs can support the activation and migration of B cells. On the other hand, under inflammatory conditions, MSCs can downregulate the production of B cells, and promote regulatory B cells (Bregs) formation [73]. The B cell-mediated immunomodulation by MSCs, can be performed either with cell-cell contact interactions or through the secretion of soluble factors. Similar to $\mathrm{T}$ cell modulation, MSCs can lead the activated B cell to cell cycle arrest or apoptosis, recruiting the Fas/Fas ligand, tumor necrosis factor-related apoptosis-inducing ligand or Apo 2 ligand (TRAIL)/DR and PD-L1/PD signaling pathways (Table 1) [72-74]. Furthermore, the secretion of anti-inflammatory cytokines such as IL-10 in combination with the TGF- $\beta 1$, HGF, PGE2 and IDO, can effectively lead the B cells to alter their responses [7274]. Indeed, it has been shown, that the above combination of soluble factors leads to the impaired migratory and homing capacity of B cells, through the downregulation of C-X-C chemokine receptor (CXCR) 4 and CXCR5. MSCs via the secretion of granulocyte-macrophage colony-stimulating factor (GM-CSF) can reduce the expression of chemokine receptors and cytokines, including CXCR4, CXCR5, IL-6 and IL-7, which further results in impaired immunoglobulin (Ig) secretion (IgM, IgG and IgA) by the plasmablast cells [72-74]. MSCs can directly induce the formation of B regulatory cells. In this process, the secreted IL-1Ra can inhibit B cell differentiation into plasmablast cells, and promote the Bregs formation (Figure 1). Bregs are characterized by a broad immunosuppressive action towards CD4+ T cells. Also, the production of IL-10 by the Bregs is responsible for the conversion of the effector CD4+ T cells, to CD4+, CD25+, FoxP3+ Tregs [72-74].

\section{MSCs-based therapy and clinical applications}

Taking into consideration the above information, regarding the immunomodulatory/immunosuppressive properties of MSCs both in native and adaptive immunity, a wide number of phase I/II and III clinical trials, are currently registered in the clinical trial database (www.clinicaltrials.gov). MSCs can elucidate their therapeutic potential in a great number of diseases, including immune-related disorders, HSCT, administration of GvHD, autoimmune diseases and recently in COVID-19 [78, 79].

\section{MSCs and HSCs transplantation}

MSCs have been shown to support the HSC engraftment and the overall hematological recovery of the patients, after autologous or allogeneic transplantation [80]. Given that, MSCs contribute to hemopoiesis and due to their broad immunoregulatory properties, these cells have been investigated as potential co-transplant agents alongside with HSCs (Table 2) [80].

Koç et al. [81], reported positive outcomes regarding the improvement of HSCs engraftment after autologous BM-MSCs infusion. In the same way, Lazarus et al. [82], conducted a multicenter clinical trial, where BM-MSCs derived from HLA-identical sibling donors, infused in patients, who received HSC transplants. Specifically, the prophylactic infusion of MSCs, (4 hours before the transplantation) was performed in 46 patients, undergoing myeloablative HSC transplantation. The patients received either BM transplants or peripheral blood HSCs. The safety and tolerability of MSCs were evaluated in this study. No infusion-related cytotoxicity, ectopic tissue formation, or severe GvHD, were reported [82]. However, the outcomes regarding the HSC transplantation, were contradictory, as no acceleration of HSC engraftment was observed, when compared with control groups. The same group also conducted another phase I-II clinical trial, to determine the feasibility and safety of culture-expanded MSCs [83]. In this study, autologous MSCs were infused in 28 breast cancer patients, who received high-dose chemotherapy and autologous HSC transplantation. MSCs were isolated from BM aspirates and culture-expanded until reached passage 6. MSCs were infused at a density of 1-2.2 $\times 10^{6}$ cells $/ \mathrm{kg}$ body weight. Again, infusion-related cytotoxicity sign was evident in the whole group of patients. Furthermore, hematopoietic recovery was rapid, as neutrophil ( $\geq 500 / \mu$ ) and platelet ( $\geq$ $20.000 / \mu \mathrm{l}$ ) engraftment was achieved after a median of 8 and 8.5 days, respectively [83].

Another meta-analysis conducted by Kallekleiv et al. [84], showed the beneficial effect of MSCs on allogeneic HSCT. Specifically, the MSCs were derived either from BM or UCB, while the HSCs were harvested 
from BM, peripheral blood, or UCB. The MSC dose, that was infused into the patients, varied greatly between the different clinical trials and ranged from $0.3 \times 10^{5} / \mathrm{kg}$ to $10 \times 10^{6} / \mathrm{kg}$ body weight. The MSC infusion was performed either before $(0.5-24 \mathrm{~h})$ or at the same time as HSCT. In these clinical trials, all patients received preconditioning regimens of total body irradiation (TBI) and/or chemotherapy, but all treatments were comparable among the patients' group of all studies. Also, the patients of the control group were transplanted with HSC, without MSC infusion, while no placebo group was involved in this set of clinical studies. Kallekleiv et al. [84], reported comparable results between the patients who received MSC infusion alongside HSCT and the control group. Specifically, the median time for HSC engraftment in patients who received MSC and those who did not was 13.4 and 17.6 days, respectively. The median for the neutrophil engraftment varied from 10 to 30 days for the MSC infused group, while for the control group was 9 to 28 days [84].

Table 2. Registered clinical trials of MSCs in GvHD and HSCT. In this table a number of representable clinical trials are summarized Data were considered as defined in the www.clinicaltrial.gov. Intravenous infusion of MSCs was performed in the listed clinical trials

\begin{tabular}{|c|c|c|c|c|c|c|}
\hline NCT number & Title & Status & Phase & $\begin{array}{l}\text { No of } \\
\text { Patients }\end{array}$ & $\begin{array}{l}\text { MSCs } \\
\text { Origin }\end{array}$ & No of MSCs \\
\hline NCT01956903 & $\begin{array}{l}\text { Treatment of Refractory Acute Graft-Versus- } \\
\text { Host Disease by Sequential Infusion of } \\
\text { Allogenic Mesenchymal Stem Cell }\end{array}$ & Completed & I/II & 15 & $\begin{array}{l}\text { Allogeneic- } \\
\text { MSCs }\end{array}$ & $\begin{array}{l}0.7 \times 10^{6} \mathrm{cells} / \\
\mathrm{kg}-2.8 \times 10^{6} \\
\text { cells } / \mathrm{kg}\end{array}$ \\
\hline NCT01222039 & $\begin{array}{l}\text { Multicenter Clinical Trial for the Evaluation of } \\
\text { Mesenchymal Stem Cells from Adipose Tissue } \\
\text { in Patients With Chronic Graft Versus Host } \\
\text { Disease }\end{array}$ & Completed & $\mathrm{I} / \mathrm{II}$ & 19 & $\begin{array}{l}\text { Allogeneic- } \\
\text { MSCs }\end{array}$ & $\begin{array}{l}1 \times 10^{6} \mathrm{cells} / \mathrm{kg}- \\
3 \times 10^{6} \mathrm{cell} / \mathrm{sg}\end{array}$ \\
\hline NCT00366145 & $\begin{array}{l}\text { Efficacy and Safety of Adult Human } \\
\text { Mesenchymal Stem Cells to Treat Steroid } \\
\text { Refractory Acute Graft Versus Host Disease }\end{array}$ & Completed & III & 260 & Undefined & $2 \times 10^{6} \mathrm{cells} / \mathrm{kg}$ \\
\hline NCT04692376 & MSC for Treatment of cGVHD After Allo-HSCT & Recruiting & ॥ & 152 & Undefined & $1 \times 10^{6} \mathrm{cells} / \mathrm{kg}$ \\
\hline NCT02824653 & $\begin{array}{l}\text { Allogenic Bone Marrow Mesenchymal Stem } \\
\text { Cells Infusion in Patients with Steroid- } \\
\text { refractory GVHD }\end{array}$ & Completed & $\mathrm{I} / \mathrm{II}$ & 10 & $\begin{array}{l}\text { Allogeneic- } \\
\text { BM-MSCs }\end{array}$ & Undefined \\
\hline NCT03106662 & $\begin{array}{l}\text { Mesenchymal Stem Cell Infusion in } \\
\text { Haploidentical Hematopoietic Stem Cell } \\
\text { Transplantation in Patients with Hematological } \\
\text { Malignancies }\end{array}$ & Completed & III & 6 & Undefined & $\begin{array}{l}2.8 \times 10^{6} \mathrm{cells} / \\
\mathrm{kg}\end{array}$ \\
\hline NCT04247945 & $\begin{array}{l}\text { Co-transplantation of MSC in the Setting of } \\
\text { Allo-HSCT }\end{array}$ & Recruiting & $\mathrm{II} / \mathrm{III}$ & 120 & Undefined & Undefined \\
\hline NCT00823316 & $\begin{array}{l}\text { Safety and Efficacy Study of Umbilical } \\
\text { Cord Blood-Drived Mesenchymal Stem } \\
\text { Cells to Promote Engraftment of Unrelated } \\
\text { Hematopoietic Stem Cell Transplantation }\end{array}$ & Completed & $\mathrm{I} / \mathrm{II}$ & 10 & UCB-MSCs & $\begin{array}{l}5 \text { doses of } \\
1 \times 10^{6} \mathrm{cells} / \mathrm{kg}\end{array}$ \\
\hline NCT04692376 & MSC for Treatment of cGVHD After Allo-HSCT & Recruiting & II & 152 & Undefined & $\begin{array}{l}8 \text { doses of } \\
8 \times 10^{6} \mathrm{cells} / \mathrm{kg}\end{array}$ \\
\hline NCT00136903 & $\begin{array}{l}\text { Safety and Efficacy Study of Adult Human } \\
\text { Mesenchymal Stem Cells to Treat Acute Graft } \\
\text { Versus Host Disease }\end{array}$ & Completed & II & 33 & Allogeneic & $2 \times 10^{6}$ cells $/ \mathrm{kg}$ \\
\hline
\end{tabular}

Similar results focused on the safety of allogeneic or autologous MSC infusion in patients with hematological malignancies, were observed also in other studies. In the study of Ball et al. [85], it reported that MSCs acted positively in 14 children undergoing haploidentical HSCT. Specifically, all children received GM-CSF mobilized CD34+ cells derived from haploidentical donors and then infused with MSCs. No adverse reactions were reported in all patients, while the HSC was successfully engrafted. Another study conducted by Macmillan et al. [86], also reported that MSCs can assist the HSC engraftment. Specifically, 15 patients enrolled in this study, who were divided into two groups. The MSCs group involved 8 patients, while the control group involved 7 patients who did not receive MSCs. In the MSC group, the cells were infused on 
the day of HSCT. The results of this study showed that all patients in the MSC group achieved stable HSC engraftment, with neutrophil engraftment $(>500 / \mu \mathrm{l})$ after 19 days and platelet engraftment $(>50.000 / \mu \mathrm{l})$ after 53 days. Moreover, it has indicated that 5 patients from the MSC group were alive and disease-free for another 6.8 years. Le Blanc et al. [87], performed MSCs infusion to enhance either the HSC engraftment or to prevent the HSC rejection after re-transplantation. The HSC donors were HLA-matched siblings for three patients and haploidentical HSCT derived from UCB for one patient. In all cases, neutrophil ( $>500 / \mu \mathrm{l})$ and platelet $(>30.000 / \mu \mathrm{l})$ engraftment was achieved within 12 days. All patients were characterized by $100 \%$ donor chimerism, even in the patients with the graft rejection, who re-transplanted [87].

In all these cases, MSCs have been shown to have a positive effect on HSCT and engraftment. This possibly is due to the unique immunosuppressive/immunomodulatory properties of MSCs and also the crosstalk with the CD34+ cells, either through the cell-cell interaction or via the production of soluble factors [80]. However, in all cases that received MSCs either prophylactically or as co-transplant agents alongside the HSCs, no severe adverse reactions were reported. In the past, it has been indicated in the literature, that MSCs can migrate through the circulation system to the lung capillary network, causing unwanted results, including embolism [66, 88-90]. In this direction, Iacobaeus et al. [91], showed that after the intravenous infusion, the MSCs were accumulated in the lung capillaries, and then cleared by the secondary lymphoid organs. In this way, the safety and tolerability of MSCs infusion in patients with hematological malignancies have been well evaluated, and MSCs may compromise an alternative quite effective cellular population for enhancing the HSC engraftment.

\section{MSCs and GvHD}

HSCT represents a well-established treatment option for malignant and non-malignant hematological disorders. In the last decades, the overall survival of patients suffering from hematological disorders has increased. Better condition regimens, availability of donor sources (BM, CD34+ from peripheral blood, UCB), type of transplantation (haploidentical, syngeneic, highly HLA-matched), high-resolution HLA-typing and prophylaxis against GvHD, have improved the HSC engraftment [92].

GvHD remains a frequent complication, especially in allogeneic HSCT and is distinguished as acute and chronic [93]. Both conditions have a significant impact on patients' survival. GvHD is a systemic inflammatory condition, where the immune cells from the donor are recognizing the host antigens as foreign and initiate an acute or a chronic immune reaction [94]. Specifically, the donor T lymphocytes are performing and HLAmediated recognition of host antigens, therefore are activated [95-98]. The specific T lymphocytes against host antigens induce damage to host tissues, in a process that involves cell-mediated and inflammatory cytokine-mediated tissue damage. Additionally, donor NK cells can further perform tissue damage through the Fas/FasL signaling pathway and the production of inflammatory cytokines $[99,100]$. This prolonged immune reaction can cause severe damage to various organs such as the liver, gut and skin, thus leading to multi-organ dysfunction [101]. Furthermore, this immune reaction can lead eventually to transplant rejection. GvHD occurrence is characterized by an overall cumulative percentage of $40 \%$ in patients receiving syngeneic (from sibling donors) HSCT and 60\% in patients receiving allogeneic HSCT [95-98]. GvHD prophylaxis may assist significantly in the reduction of this issue, however, the life-threatening complications are limiting the application of allogeneic HSCT [92]. Acute GvHD (aGvHD) can be occured in 30-50\% of recipients and 14\% of them can suffer from severe aGvHD (grade 3-4) [102]. Chronic GvHD (cGvHD) affects more than 60\% (30-70\%) of patients that are receiving allogeneic HSCT [97]. Risk factors that can lead to the initiation of GvHD are the HLA disparity, donor type, source of HSCs, recipient age, type of myeloablative and prophylaxis regimens [92]. However, despite the availability of better treatment options, steroid-resistant GvHD can occur. Steroid-resistant GvHD is defined as the lack of response after 3-7 days of corticosteroid treatment [92, $97,102]$. The overall survival rate of patients that are suffering from steroid-resistant GvHD is less than 30\% in the 1st year [103]. Moreover, there is no standard approach as second-line therapy in those patients. The development of alternative treatments for the proper administration of GvHD and steroid-resistant GvHD is of paramount importance and may be crucial for the survival of those patients [92, 102]. 
In this direction, MSCs derived either from BM, AT and UC can serve as a promising cellular therapy. Currently, 46 clinical trials have been officially registered (Table 2). MSCs can directly modulate the activated donor $\mathrm{T}$ lymphocytes either by cell-cell contact interactions or through the secretion of soluble factors, including IDO, PGE2, IL-10, TGF- $\beta 1$, NO, HLA-G and TSG-6, as has been described previously [34]. In addition, MSCs can be activated by $\mathrm{C} 3$ of the complement system and can secrete the factor $\mathrm{H}$ [64]. Factor $\mathrm{H}$ is responsible for the inhibition of complement activation by limiting the C3 and C5 convertases activity [64]. Due to their broad immunosuppressive/immunomodulatory properties and significant role in immunity, MSCs have been evaluated as a potential cellular therapy in a great number of clinical trials focused on patients with aGvHD [96-103]. Specifically, Ringden et al. [104], conducted a pilot study, involving eight patients with severe GvHD grade III-IV after allogeneic HSCT. Of those patients, 6 responded completely to the treatment. Taken into consideration these results, a multicenter study, involved 5 European centers and 55 patients was performed [105]. This study was performed from October 2001 to 2007, and the patients received BM-MSCs obtained from matched sibling donors, haploidentical donors, and third-party HLA mismatched donors [105]. The patients received 1-5 MSCs doses, and each dose consisted of 1-10 $\times 10^{6} \mathrm{MSCs} / \mathrm{kg}$ of body weight. The results of this study showed that 30 patients responded completely and 9 showed clinical improvement. Furthermore, no severe adverse reactions were reported after the infusion of MSCs, even in the non-HLA-matched MSCs group [105]. Also, complete responders to MSCs infusion were characterized by lower transplantation-related mortality (TRM) 1 year after infusion (37\% vs. $72 \%)$ and higher overall survival 2 years after the HSCT (53\% vs. 16\%). In another multicenter study, which was performed in 3 Brazilian hospitals, between 2007 and 2015, 46 patients with GvHD have received MSC infusions [106]. This study enrolled 16 pediatric and 30 adult patients who suffered from steroid-refractory aGvHD grade III (21.7\%) and grade IV (78.3\%). On average 3 doses of MSCs at a density of $6.8 \times 10^{6} / \mathrm{kg}$ body weight, were infused in all patients. This study showed that 23 patients responded and among them, 3 patients had a complete response. Also, the overall survival of the patients at day $+100,1$ year and 2 years were $34.4 \%$, $19.6 \%$ and $17.4 \%$, respectively. No severe adverse reactions were observed after the MSC infusion [106]. Similar results were obtained from the study of Dalowski et al. [107]. Specifically, this study enrolled 58 patients, of which 79\% were suffered from aGvHD grade IV. Each patient received on average 2 MSCs doses at a density of $0.99 \times 10^{6} / \mathrm{kg}$ body weight. Of the 58 patients, 27 were responded and 5 completely responded to the MSC treatment. The estimated 1-year overall survival (OS) was 19\%, a result which was similar with the aforementioned study [107]. The study of Liu et al. [108] also mentioned that co-transplantation of MSCs may act positively in patients suffering from severe aplastic anemia (SAA) and who received haploidentical HSCT. In this study, 44 patients diagnosed with SAA were involved. Among them, 13 patients were considered to have very severe SAA. The median age was 24 years. In addition, $75 \%$ of the patients did not respond to corticosteroid treatment against the GvHD. Each patient received 3 doses of MSCs at a median density of $3.6 \times 10^{6} / \mathrm{kg}$ body weight. The first dose of MSCs was administrated $6 \mathrm{~h}$ before the HSCT, and the second dose at day 14. A third dose also could be applied after 4 weeks in patients with poor graft function or severe GvHD. After HSCT, neutrophil ( $>500 / \mu \mathrm{l}$ ) and platelet ( $>30.000 / \mu \mathrm{l}$ ) engraftment were performed on average at 12 and 19 days, respectively. Ninty-seven point six percent of patients achieved hematopoietic reconstitution and sustained full donor chimerism. The incidence for aGvHD grade II-IV was $29.3 \%$ and for cGvHD was 14.6\% [108]. The above data strongly indicated that MSC infusion could reduce the risk of graft failure and severe GvHD occurrence after haploidentical HSCT in patients with SAA. Also, the authors of this study, speculated that cell-cell contact interactions and secretion of soluble factors were the main involved mechanisms that MSCs used. MSCs could create a favorable BM microenvironment, before the transplantation, thus enhancing the engraftment of HSCs [105-108]. Additionally, the prevention of GvHD could be mediated through the immunoregulatory/immunosuppressive properties of MSCs to donor T cells.

\section{MSCs and autoimmune disorders}

Besides the HSCT and GvHD administration, MSCs seem to play a significant role in autoimmune disorders. Autoimmune disorders are the leading cause of death, especially in women up to 64 years of age [109]. In literature, there is great evidence for using MSCs in systemic lupus erythematosus (SLE), lupus nephritis (LN), 
rheumatoid arthritis (RA), multiple sclerosis (MS) and amyotrophic lateral sclerosis (ALS) [110-113]. To date, there is a plethora of new treatment strategies, including specific monoclonal antibodies (mAbs) against B lymphocytes, immunosuppressive agents, corticosteroid treatment and non-steroidal drugs. Significant adverse effects are accompanying the above treatments however, most of which can reduce the manifestations caused by the autoimmune disorders, improving the quality of patient's life, and extending also the patient's OS rate [109-113]. However, novel cellular therapies, such as the MSCs or T-reg infusion, without having adverse reactions, must be evaluated, providing to clinical doctors more available treatment options. Indeed, cellular therapies may be one of the broadly applicable translational strategies for autoimmune disorders.

\section{Systemic lupus erythematosus}

SLE is a multisystemic autoimmune disorder, which can damage several organs and is characterized by clinical heterogeneity. The prevalence of SLE is 30 out of 100,000 people and the epidemiological data showed greater incidence rates in Asian people compared to the European people [114]. SLE is characterized by inflammatory-mediated injury, where the immune cells are playing a crucial role. Indeed, SLE patients have overstimulated B and T cell subsets. These overactivated immune cell populations are producing large quantities of inflammatory cytokines and self-antibodies, which are inducing severe damage to multiple organs [115]. It has been shown that the olfactory 1/early B cell factor-associated zing finger protein (OAZ) is highly expressed in patients suffering from SLE $[116,117]$. OAZ is speculated to play a pivotal role in B cell proliferation and differentiation to plasmablasts, which further leads to the high secretion of IgG, IgM and anti-nuclear antibodies [116, 117].

In this direction, the immunosuppressive properties exerted by MSCs can be proven useful to halt the B cell proliferation and differentiation (Table 3). Previous studies have demonstrated that SLE patients are characterized by autophagy-activated CD4+ T helper and CD8+ cytotoxic T cells $[118,119]$. Specifically, CD4+ and CD8+ T cell subsets are characterized by defective mitochondria, mitochondrial hyperpolarization, ATP depletion and increased apoptosis [118, 119]. MSCs can effectively rescue the T cells from apoptosis using tunneling nanotubes to transfer their mitochondria. In this way, the respiratory mitochondria accumulation can be inhibited, thus downregulated the caspase and the whole autophagy program $[110,120]$. In addition, the MSCs can modulate the CD4+ CD25+ FoxP3 Tregs in SLE patients [121]. Specifically, it has been shown that IFN- $\gamma$ activated MSCs can produce the HLA-G (soluble and membrane form). HLA-G has been proven to be involved in the immunosuppression exerted by MSCs. Also, there is evidence that the soluble form of HLA-G (HLA-G5) can contribute to the Tregs proliferation [75], thus assisting significantly to the immune system regulation, exerted by MSCs. In this way, MSCs may potentially be utilized as an alternative therapeutic option, in order to improve the SLE patient's condition.

\section{Crohn's disease}

Crohn's disease (CD) is an autoimmune disorder of undefined etiology, which is responsible for the inflammation and fistulization induction to the entire gastrointestinal tract [122]. Patients with CD often suffer from diarrhea, fever, abdominal distension and weight loss. It is thought that CD occurrence may be due to impaired cytokine secretion by the macrophages, hampering in this way the innate and adaptive immunity $[122,123]$. This can cause a microbial-induced inflammatory response in the colon. Also, CD patients are characterized by overactive Th1 and Th17 cytokine secretion [100, 110, 123]. Primary treatment of CD involves initially the remission of acute symptoms, performed mostly by the high bacterial load. Antibiotics, anti-inflammatory drugs and corticosteroids are given to the CD patients [110, 124]. Also, co-administration with immunomodulators such as methotrexate, infliximab, adalimumab, etc., are often selected as primary therapy [124]. Unresponsive CD patients to treatment strategies must undergo surgical intervention. Specifically, removal of the infected part of the intestine is performed, where the partial or full blockage exists. However, a great percentage of patients will need the second resection, within 5 years $[110,125]$.

Alternative treatment options may involve the use of cellular therapies and importantly the MSCs infusion in CD patients [125]. There are a few clinical trials which involve the infusion of allogeneic or autologous MSCs in CD patients (Table 3). Specifically, Onken et al. [126], reported the successful CD administration 
of 10 patients who were unresponsive to steroid treatments. Patients were randomized and intravenously infused with either low dose $\left(2 \times 10^{6}\right.$ cells $\left./ \mathrm{kg}\right)$ or high dose $\left(8 \times 10^{6}\right.$ cells $\left./ \mathrm{kg}\right)$ of allogeneic third-party BMMSCs. In disease condition evaluation, nine out of ten patients were characterized by a decrease in Crohn's Disease Activity Index (CDAI) score by day 28. The clinical response of patients defined as $\geq$ the 100-point reduction in CDAI. This response was evident in 3 patients (33\%) by day 14. In another study conducted by Ciccocioppo et al. [127], autologous BM-MSCs were administered in 9 patients [127]. Two doses with MSCs at a density of $1-2 \times 10^{6} / \mathrm{kg}$ were intravenously infused in each patient. All patients previously have followed corticosteroid treatment, but the overall response was not adequate. Three out of nine patients had a reduction of at least 70 points in CDAI, but the majority of the patients of this study were worsened, requiring either rescue medication or surgery. Also, adipose-derived MSCs obtained from lipoaspirate have been used for their potential effect as local treatment of fistulae in CD patients [128]. Specifically, in a phase II multicenter randomized control clinical trial, AT-MSCs were locally given to patients with complex perianal fistulas. AT-MSCs at a density of $20 \times 10^{6}$ cells/kg were combined with fibrin glue and locally administrated. No evident fistula healing was observed after 8 weeks of MSCs administration. However, a second dose with a higher number of AT-MSCs $\left(40 \times 10^{6} / \mathrm{kg}\right)$ in combination with fibrin glue, was locally infused. Improvement in fistula healing was observed in 17 (71\%) out of 24 patients, compared to 4 of 25 patients (control group), who received only the fibrin glue [128].

Table 3. Registered clinical trials of MSCs in SLE, CD, MS and ALS. In this table a number of representable clinical trials are summarized. Data were considered as defined in the www.clinicaltrial.gov

\begin{tabular}{|c|c|c|c|c|c|c|}
\hline NCT number & Title & Status & Phase & $\begin{array}{l}\text { No of } \\
\text { patients }\end{array}$ & MSCs origin & No of MSCs \\
\hline NCT04184258 & $\begin{array}{l}\text { Treatment of Systemic Lupus Erythematosus } \\
\text { with Pooled Allogenic Mesenchymal Stem } \\
\text { Cells }\end{array}$ & Completed & $1 / I I$ & 7 & $\begin{array}{l}\text { Pooled- } \\
\text { MSCs from } \\
\text { olfactory } \\
\text { mucosa }\end{array}$ & Undefined \\
\hline NCT02633163 & $\begin{array}{l}\text { Phase } 2 \text { Trial of Mesenchymal Stem Cells } \\
\text { in Medication-induced Systemic Lupus } \\
\text { Erythematosus }\end{array}$ & Recruiting & II & 81 & Undefined & $\begin{array}{l}1 \times 10^{6} \text { cells } / \\
\mathrm{kg}\end{array}$ \\
\hline NCT03562065 & $\begin{array}{l}\text { Treatment of Refractory Systemic Lupus } \\
\text { Erythematosus by Allogeneic Mesenchymal } \\
\text { Stem Cells Derived from the Umbilical Cord }\end{array}$ & $\begin{array}{l}\text { Not yet } \\
\text { recruiting }\end{array}$ & $I / I I$ & 10 & UC-MSCs & $\begin{array}{l}1 \times 10^{6} \text { cells/ } \\
\mathrm{kg}-4 \times 10^{6} \\
\text { cells } / \mathrm{kg}\end{array}$ \\
\hline NCT01157650 & $\begin{array}{l}\text { Treatment of Fistulous Crohn's Disease by } \\
\text { Implant of Autologous Mesenchymal Stem } \\
\text { Cells Derived from Adipose Tissue }\end{array}$ & Completed & $\mathrm{I} / \mathrm{II}$ & 15 & $\begin{array}{l}\text { Autologous } \\
\text { AT-MSCs }\end{array}$ & Undefined \\
\hline NCT04519671 & $\begin{array}{l}\text { Mesenchymal Stem Cells for the Treatment of } \\
\text { Perianal Fistulizing Crohn's Disease }\end{array}$ & Recruiting & $\mathrm{I} / \mathrm{II}$ & 20 & Undefined & $\begin{array}{l}1 \text { dose of } \\
75 \times 10^{6} \text { cells }\end{array}$ \\
\hline NCT04519684 & $\begin{array}{l}\text { Study of Mesenchymal Stem Cells for } \\
\text { the Treatment of Ileal Pouch Fistula's in } \\
\text { Participants with Crohn's Disease }\end{array}$ & Recruiting & $I / I I$ & 20 & $\begin{array}{l}\text { Allogeneic } \\
\text { BM-MSCs }\end{array}$ & $\begin{array}{l}1 \text { dose of } \\
75 \times 10^{6} \text { cells }\end{array}$ \\
\hline NCT01377870 & $\begin{array}{l}\text { Evaluation of Autologous Mesenchymal } \\
\text { Stem Cell Transplantation (Effects and Side } \\
\text { Effects) in Multiple Sclerosis }\end{array}$ & Completed & $I / I I$ & 22 & $\begin{array}{l}\text { Autologous } \\
\text { BM-MSCs }\end{array}$ & Undefined \\
\hline NCT03778333 & $\begin{array}{l}\text { Mesenchymal Stem Cells for Progressive } \\
\text { Multiple Sclerosis_Sweden }\end{array}$ & Completed & 1 & 7 & $\begin{array}{l}\text { Autologous } \\
\text { BM-MSCs }\end{array}$ & $\begin{array}{l}1 \text { dose of } 1-2 \\
\times 10^{6} \text { cells } / \mathrm{kg}\end{array}$ \\
\hline NCT01759797 & $\begin{array}{l}\text { Intravenous Transplantation of Mesenchymal } \\
\text { Stem Cell in Patients With ALS }\end{array}$ & Completed & 1 & 6 & $\begin{array}{l}\text { Autologous } \\
\text { BM-MSCs }\end{array}$ & $\begin{array}{l}2 \times 10^{6} \text { cells/ } \\
\mathrm{kg}\end{array}$ \\
\hline NCT01051882 & $\begin{array}{l}\text { Autologous Cultured Mesenchymal Bone } \\
\text { Marrow Stromal Cells Secreting Neurotrophic } \\
\text { Factors (MSC-NTF), in ALS Patients }\end{array}$ & Completed & $1 / I I$ & 12 & $\begin{array}{l}\text { Neurotrophic } \\
\text { factors from } \\
\text { autologous } \\
\text { BM-MSCs }\end{array}$ & $\mathrm{N} / \mathrm{A}$ \\
\hline
\end{tabular}

All these studies showed that MSCs (obtained from all sources) have beneficial properties either intravenously infused or locally administrated. MSCs can home at the sites of injury via the expression of adhesion molecules such as CD44, CD29, ICAM-1 and VCAM-1. Then, they can be activated by the presence of either the bacterial burden or the overactivated immune cells. Therefore, the immunomodulatory properties of MSCs can regulate positively the autoimmune microenvironment. 


\section{Multiple sclerosis and amyotrophic lateral sclerosis}

MS is an autoimmune disorder, inducing neuron demyelination of the central nervous system $[129,130]$. Mostly, accumulation of demyelinating lesions in white and grey matters in the brain and spinal cord, are performed $[129,130]$. The basis of this autoimmune neurodegenerative disease is the activation and mobilization of T lymphocytes against the myelin [130]. In MS pathogenic T helper (Th) 17 and CD8+ autoreactive $\mathrm{T}$ cells against the myelin exist [130]. In the demyelinated lesion, microglia and macrophages have also been observed. In the context of myelin antigens recognition, B cells are not limited to antibody production but are playing a crucial role in the antigen presentation and modulation of $\mathrm{T}$ cells $[129,130]$. In this process, specific sets of cytokines are secreted by B cells, which are over-activating, even more, the autoreactive T cells. The therapeutic approaches, utilizing mostly corticosteroids and IFN- $\beta$, are compromising disease-modifying therapies [131]. These advanced therapies can exert anti-inflammatory properties, which may assist in reducing the rate of relapses.

Except for the above therapeutic strategies, modern advanced MS treatments must be investigated, to properly handle non-responsive patients. In such a way, stem cell therapies and especially the MSCs infusion, seem very promising. To date, more than 29 clinical phase 1 or phase 2 trials, have been registered to clinicaltrials.gov (Table 3). In most of the clinical trials, the safety and tolerance of the infused MSCs to the patients were initially evaluated. However, a number of these registered clinical trials, demonstrate improvement in the quality of patients' life. Indeed, Karussis et al. [132-134], have performed a great number of studies, where the MSCs infusion, is performed. In a pilot study, where the safe and tolerability of MSCs were evaluated, no significant clinical response or adverse events were observed in 10 patients, after the intrathecally MSCs infusion [134]. Karussis et al. [134], observed that following the MSCs infusion, an increased number of CD4+CD25+T regulatory cells, in parallel with decreased proliferative responses of autoreactive T cell subsets, were observed. In another study, performed by Connick et al. [135], the MSCs had a benefit in MS treatment. Specifically, this study enrolled 10 patients, who received intravenously MSCs at a density of 1-10 $\times 10^{6}$ cells $/ \mathrm{kg}$. All patients, characterized by improvement on measures of visual function, while the general disability was also reduced after the MSCs infusion.

Another recently contacted study by Iacobaeus et al. [91], presented the potential positive effects of BMMSCs in MS patients. Specifically, autologous BM-MSCs were infused to 10 MS patients aged 18-50 years, which have a baseline expanded disability status scale (EDSS) 3.0-7.0 and MS disease duration of 2-20 years. Also, the patients were unresponsive to treatment with disease-modifying therapies (DMTs) and have not received any immunosuppressive therapy within 3 months, or IFN- $\beta$ or corticosteroids within 30 days prior to the MSCs infusion. BM-MSCs intravenously infused at a density of $1-2 \times 10^{6}$ cells $/ \mathrm{kg}$ body weight. BM-MSCs were safe and well-tolerated by the patients, and no severe adverse reactions were observed. Immunoprofiling of MS patients suggested that MSCs could assist in the increase of the circulating Tregs, which can further induce long-term tolerogenic effects and therapeutic potential. Also, stabilization of specific miR expression in the plasma of MS patients was followed by the MSCs infusion. These specific set of miRs, are related to signaling pathways and especially with the Hippo and FoxO signaling pathways [91]. Their dysregulation has been linked to various neurodegenerative diseases such as MS, amyotrophic lateral sclerosis, and Alzheimer's disease. In the same way, as MS, ALS is a lethal neurodegenerative disease, where selective degeneration of upper and lower motor neurons is performed. The main symptoms of ALS are muscle weakness, cramps, twitching, and problems in speaking. It is estimated that in Europe, the ALS incidence is 2 to 3 cases/100,000 people [136]. Currently, several clinical trials have been performed and evaluated as a potential stem cell therapy in ALS patients. Initially, the safe and tolerability of BM-MSCs in ALS patients were shown in the studies conducted by Nabavi et al. [137]. In those studies, intravenous and intrathecal administration of autologous BM-MSCs at a density of $2 \times 10^{6}$ cells $/ \mathrm{kg}$, were performed. No major adverse events were observed after the MSCs administration and a 12-month follow-up of all patients. Moreover, the ALS functional rate scale (ALSFRS) score and forced vital capacity (FVC) percentage significantly reduced in all patients from both groups. In another study, conducted by $\mathrm{Oh} \mathrm{KW}$ et al. [138], the repeated injections of BM-MSCs were also shown to be safe. In this study, two repeated intrathecal infusions of autologous BM-MSCs, were performed to ALS patients. Specifically, ALS patients were randomly divided into the control group, which received riluzole, and the 
group that was administered with 2 BM-MSCs injections. The mean changes in ALSFRS-revised (ALSFRS-R) scores from baseline to 6 months, were reduced in the MSC group in comparison with the control group. In addition, an increase in anti-inflammatory cytokines, with the subsequent decrease in pro-inflammatory cytokines, were detected in the cerebrospinal fluid, in patients belonging to MSC group. Furthermore, the authors suggested that due to microenvironment cues, induced by ALS, MSCs successfully adopted an antiinflammatory phenotype. Given that, the growth factors and especially the neurotrophic ones, exerted by MSCs, may have a positive effect in rescuing the motor neurons in ALS patients, the researchers evaluated different treatment protocols. Specifically, Petrou et al. [139], performed intrathecally and/or intramuscular injections of neurotrophic factors, exerted by in vivo culture-expanded MSCs. This novel treatment was found to be safe and well-tolerated by ALS patients. The rate of disease progression was reduced during the 6 months after the neurotrophic factors injection. Specifically, $87 \%$ of the patients were responded to the treatment, showing at least 25\% improvement in ALSFRS-R and FVC scores, within 6 months after the injections.

The performed and ongoing clinical trials have provided enough evidence for the safety and tolerability of autologous and allogeneic MSCs administration in MS and ALS. Indeed, autologous MSCs infusion may present some advantages over the allogeneic, therefore is of paramount importance to evaluate the characteristics of the autologous MSCs. BM-MSCs obtained from MS and ALS patients can efficiently proliferate under in vitro conditions and have shown a differentiation potential towards mesodermal lineages $[136,140]$. BMMSCs obtained from MS and ALS patients have shown the same proliferation rate, immunophenotypic profile and differentiation potential as the BM-MSCs obtained from healthy donors [136, 141]. However, reports are indicating that BM-MSCs derived from MS and ALS patients have limited proliferation potential and exhibited accelerated senescence, telomere shorting and reduced telomerase activity. Furthermore, patients' MSCs are characterized by different transcriptional patterns associated with less immunomodulatory effects, in comparison to BM-MSCs from healthy donors [136, 141]. Considering the above data, it can be assumed that the overall patient's condition, disease severity and age, may significantly affect the BM-MSCs characteristics. Therefore, the quality control of MSCs obtained from MS patients may be valuable, in order to select the optimum treatment between autologous and allogeneic therapy [136, 141].

\section{Application of MSCs in COVID-19}

COVID-19 is an emerging disease, which initially was started in December 2019, in Wuhan, China [142]. The zoonotic transmission of a new coronavirus strain was responsible for the COVID-19 outbreak. In March 2020, the International Committee on Taxonomy of Viruses (ICTV) has renamed it severe acute respiratory syndrome coronavirus-2 (SARS-CoV-2) [143, 144]. Until now, more than 115 million new cases have been reported, more than 2.56 million people have died, and more than 65.1 million people have recovered. Recently, also new variants of coronavirus have been detected, including the B.1.1.7 (United Kingdom variant), B.1.351 (South Africa variant) and P.1 (Brazil variant) [145]. These variants seem to spread more easily, produce a higher virus load and are associated with an increased risk of death, compared to the initially detected virus.

Severe acute respiratory distress syndrome (ARDS) is caused by the SARS-CoV-2 and its variants, in infected patients. Moreover, ARDS is related to lung damage and tissue fibrosis. Increased levels of inflammatory cytokines, such as IL-2, IL-6, IL-7, GSCF, IP10, MCP1, MIP1A, and TNF- $\alpha$, an event which is known as "cytokine storm", has been observed in severely conditioned patients [146]. Except for lung damage, SARS-CoV-2 may infiltrate other organs such as the heart, kidney, and brain, causing cardiomyopathy, arrhythmias, kidney failure, and encephalitis, respectively [146]. To properly handle disease transmission, several treatments have been proposed.

Recently the production and the broad dissemination of specialized vaccines against COVID-19, seem to halt the global burden of the pandemic [146]. With the knowledge that COVID-19 causes significant modifications to the immune system of the infected patients, alternative strategies, involving advanced cellular therapies, must also be evaluated.

MSCs may beneficially assist in the administration of the COVID-19 pandemic, as an available treatment option [147-151]. Currently, over 30 clinical trials, where MSCs can be potentially applied in COVID-19 as 
therapeutic agents, have been officially registered (Table 4). Leng et al. [152], performed the first multicenter study, including a great number of hospitals in China, and reported that MSCs have a positive outcome in critically diseased COVID-19 patients. In this study, clinical-grade MSCs were intravenously infused in 7 patients diagnosed with SAR-CoV-2 and also characterized by increased inflammatory cytokines levels. A total number of $1 \times 10^{6} \mathrm{MSCs} / \mathrm{kg}$ body weight were infused to the patients with a rate of $40 \mathrm{drops} / \mathrm{min}$. MSCs were well tolerated by the patients and were capable to improve their severe condition. Indeed, 2-4 days after the MSC infusion, severe symptoms including fever, oxygen saturation and cough were improved. Mass cytometry analysis revealed that the overactivated CXCR3+CD4+ T cells, CXCR3+CD8+ T cells, and CXCR3+NK cells disappeared and that the CD14+CD11c+CD11bmid DCs reversed to normal conditions. The majority of the patients were discharged from the hospital. Also, 1 severely conditioned patient achieved to exit from the ICU and successfully recovered. On the contrary, one patient from the placebo group died, one developed ARDS, and one was in stable condition [152].

Table 4. Registered clinical trials of MSCs in COVID-19. In this table, a number of representable clinical trials are summarized. Data were considered as defined in the www.clinicaltrial.gov. Intravenous infusion of MSCs was performed in the listed clinical trials

\begin{tabular}{|c|c|c|c|c|c|c|}
\hline NCT number & Title & Status & Phase & $\begin{array}{l}\text { No of } \\
\text { patients }\end{array}$ & $\begin{array}{l}\text { MSCs } \\
\text { origin }\end{array}$ & No of MSCs \\
\hline NCT04444271 & $\begin{array}{l}\text { Mesenchymal Stem Cell Infusion for COVID-19 } \\
\text { Infection }\end{array}$ & Recruiting & II & 10 & $\begin{array}{l}\text { Frozen } \\
\text { MSCs }\end{array}$ & $2 \times 10^{6} \mathrm{cells} / \mathrm{kg}$ \\
\hline NCT04713878 & $\begin{array}{l}\text { Mesenchymal Stem Cells Therapy in Patients } \\
\text { With COVID-19 Pneumonia }\end{array}$ & Completed & $\mathrm{N} / \mathrm{A}$ & 21 & Undefined & Undefined \\
\hline NCT04565665 & $\begin{array}{l}\text { Cord Blood-Derived Mesenchymal Stem Cells } \\
\text { for the Treatment of COVID-19 Related Acute } \\
\text { Respiratory Distress Syndrome }\end{array}$ & Recruiting & 1 & 70 & UCB-MSCs & Undefined \\
\hline NCT04416139 & $\begin{array}{l}\text { Mesenchymal Stem Cell for Acute Respiratory } \\
\text { Distress Syndrome Due for COVID-19 }\end{array}$ & Recruiting & II & 10 & $\begin{array}{l}\text { Allogeneic- } \\
\text { MSCs }\end{array}$ & $1 \times 10^{6} \mathrm{cells} / \mathrm{kg}$ \\
\hline NCT04252118 & $\begin{array}{l}\text { Mesenchymal Stem Cell Treatment for } \\
\text { Pneumonia Patients Infected With COVID-19 }\end{array}$ & Recruiting & I & 20 & Undefined & $\begin{array}{l}3 \text { times of } 3 \times \\
10^{7} \text { cells }\end{array}$ \\
\hline NCT04313322 & $\begin{array}{l}\text { Treatment of COVID-19 Patients Using } \\
\text { Wharton's Jelly-Mesenchymal Stem Cells }\end{array}$ & Recruiting & 1 & 5 & WJ-MSCs & Undefined \\
\hline NCT04336254 & $\begin{array}{l}\text { Safety and Efficacy Study of Allogeneic Human } \\
\text { Dental Pulp Mesenchymal Stem Cells to Treat } \\
\text { Severe COVID-19 Patients }\end{array}$ & Recruiting & $I / I I$ & 20 & $\begin{array}{l}\text { Allogeneic } \\
\text { Dental Pulp } \\
\text { MSCs }\end{array}$ & $3 \times 10^{7}$ cells \\
\hline NCT04611256 & $\begin{array}{l}\text { Mesenchymal Stem Cells in Patients } \\
\text { Diagnosed With COVID-19 }\end{array}$ & Recruiting & 1 & 20 & AT-MSCs & $1 \times 10^{6} \mathrm{cells} / \mathrm{kg}$ \\
\hline NCT04346368 & $\begin{array}{l}\text { Bone Marrow-Derived Mesenchymal Stem } \\
\text { Cell Treatment for Severe Patients With } \\
\text { Coronavirus Disease-19 (COVID-19) }\end{array}$ & $\begin{array}{l}\text { Not Yet } \\
\text { Recruiting }\end{array}$ & $\mathrm{I} / \mathrm{II}$ & 20 & BM-MSCs & $1 \times 10^{6} \mathrm{cells} / \mathrm{kg}$ \\
\hline NCT04366271 & $\begin{array}{l}\text { Clinical Trial of Allogeneic Mesenchymal Cells } \\
\text { From Umbilical Cord Tissue in Patients With } \\
\text { COVID-19 }\end{array}$ & Recruiting & II & 106 & $\begin{array}{l}\text { Allogeneic } \\
\text { UC-MSCs }\end{array}$ & Undefined \\
\hline
\end{tabular}

Moreover, MSCs can reduce the damage of alveolar epithelium and lung fibrosis, by exerting key regenerative properties. Based on previous literature, MSCs can accumulate for a short period to the lung capillary vessels. Upon migration and proper adhesion to the damaged alveolar tissue, MSCs can produce increased levels of several growth factors, such as TGF- $\beta 1$, vascular endothelial growth factor (VEGF), HGF, epidermal growth factor (EGF), and insulin-like growth factor (IGF) [146]. This set of growth factors are responsible for important regenerative aspects, including the differentiation of progenitor cells to alveolar epithelial cells, mobilization of M2 macrophages, and reduction of scar tissue formation. The regenerative potential of MSCs to the damaged lung tissue was confirmed by the reversion of ground-glass opacity in lungs of COVID-19 patients, several days after the MSCs infusion [146].

\section{MSC therapy: autologous or allogeneic?}

Currently, a large number of clinical trials have elucidated the potential either of autologous or allogeneic MSC therapy. However, there is a possibility that third-party MSCs obtained from healthy donors, may be 
characterized by better immunomodulatory-immunosuppressive properties, compared to MSCs obtained from patients [153].

It has been mentioned by different research groups, that MSCs obtained from patients suffering from autoimmune disorders, such as MS and ALS, are exhibited impaired functional properties, compared to those obtained from healthy donors [140]. Indeed, the study of Redondo et al. [154], showed, that MSCs obtained from MS patients, were characterized by impaired proliferation, CFUs development and increased senescence compared to MSCs from healthy donors. However, in this study, no further evaluation regarding the immunoregulatory properties of MSCs was performed [154]. On the other hand, third-party adult MSCs derived from healthy donors presented greater trilineage differentiation potential, proliferation and decreased senescence. In addition, fetal MSCs (derived from extraembryonic tissues e.g., placenta, amniotic fluid, and umbilical cord) may have better immunoregulatory potential compared to the adult MSCs [140].

Fetal MSCs are characterized by limited epigenetic mutations, increased telomerase activity and longer telomeres. Also, fetal MSCs have been exposed to less oxidative stress compared to the other sources [155]. Moreover, WJ-MSCs are expressing the HLA-G, a non-classical HLA class I molecule, with known immunoregulatory properties [32]. It is located to chromosome 6 (locus p21.1-21.3) in humans and is characterized by membrane-bound isoforms (HLA-G1-4) and by soluble isoforms (HLA-G5-7) [32]. It has been shown also that the HLA-G-related immunosuppressive properties are better exerted from fetal MSCs compared to those from the adult origin [156]. HLA-G for the first time was detected in pregnancy, where it can exert its tolerogenic effects on the fetus [157]. Specifically, HLA-G is expressed from the trophoblast, placenta and other extraembryonic tissues, and it is implicated in the immune tolerance of the semiallogeneic fetus through the interplay between NK and CD8+ T cells [157]. From research and clinical evidence, it has been shown that HLA-G may exert a broader immunoregulatory effect on immune cells, including macrophages, $\mathrm{T}$ and B cells [156]. Due to its immunoregulatory potential, HLA-G + WJ-MSCs can be considered as a possible stem cell treatment for immune-related diseases.

Furthermore, MSCs are characterized by limited expression of the HLA class II molecules. Therefore, allogeneic MSC therapy is considered safe and tolerogenic, without causing significant adverse reactions to the patients. Indeed, Le Blanc et al. [158], showed that MSCs only intracellularly expressed the HLA class II molecules. No costimulatory molecules including the CD26, CD80 and CD86 are expressed either by an adult or fetal MSCs. Moreover, after IFN- $\gamma$ stimulation of MSCs, only partial expression of HLA class II, was observed. However, IFN $-\gamma$ activated MSCs were not immunogenic, as they did not stimulate the allogeneic lymphocytes, thus potentially compromise an allogeneic treatment.

Since the questions regarding the use of a universal MSC donor, have not been answered, the application of both types of infusion (autologous or allogeneic) must be comprehensively evaluated. Besides the above issue, MSCs exert key therapeutic properties, through the direct contact or the paracrine secretion of immunomodulatory molecules, that are beneficial as novel stem cell therapy $[16-18,159]$.

\section{Conclusions}

A great burden of information is linking the therapeutic effects exerted by MSCs in several human disorders. MSCs, besides the regenerative medicine and tissue engineering approaches, can be utilized effectively in immune-related disorders, including the HSCT, GvHD, CD, SLE, MS, ALS, and COVID-19. Currently, a large number of clinical trials are performed, where the beneficial effects of MSCs are evaluated. Currently, MSCs are considered immune-privileged cells, thus can be used either in an autologous or allogeneic manner [153].

In the context of utilization of MSCs as stem cell therapy, isolation, characterization and banking of either autologous or third party MSCs, under well-defined conditions must be established. The future perspectives of banked MSCs shall include their application in regenerative medicine and tissue engineering (e.g., as wound and burn healing applications), the development of specialized cellular populations (e.g., induced pluripotent stem cells) and advanced cellular therapies (e.g., specific MSCs subsets, such as CD146+ or CD271+ MSCs, MSCs with unique protective effects, restricted to the donor-recipient HLA system). 
Besides the utilization of MSCs as a promising stem cell therapy, also other cellular populations may be considered as candidates for regenerative medicine applications. Indeed, progenitor cells (such as cardiac, neural, endothelial progenitor cells), are characterized by key regenerative properties. However, recent evidence indicated that progenitor cells may implicate the regulation of patient's immune system, upon administration [160]. Specifically, it has been shown that cardiac progenitor cells can suppress the CD4+ T helper cell-mediated immune responses in a cell-cell-dependent manner [161]. In the same way as MSCs, cardiac progenitor cells (CPCs) can inhibit the effector T cells, through the PD-L1/PD1 interaction. However, the B cells immunoregulation mediated by CPCs is limited, compared to MSCs. Also, the suppression of antibody production by CPCs is still controversial, and more research is required in this field. It has been shown that CPCs may decrease the levels of IgM, IgG1 and IgG3 [161]. However, MSCs have greater immunoregulatory potential, which is exerted both by cell-cell interaction and soluble factors secretion. It has been shown, that MSCs can produce greater amounts of extracellular vesicles (EVs) containing antiinflammatory mediators compared to progenitor cells, which can regulate effectively both innate and adaptive immunity [162]. Considering the above information, progenitor cells may be used as candidate cellular populations for personalized therapy. However, progenitor cells and iPS are characterized by demanding in vitro handling, limited proliferation potential and genome instability, compared to MSCs [163]. Therefore, progenitor cells may be used in regenerative medicine applications, but more research is required, to develop effective personalized therapies. The use of MSCs in pathological conditions and human diseases is classified as stem cell-based therapies [12]. In this way, the guidelines of the ISCT must be followed, to assure the quality characteristics of MSCs. According to the "Guidance of Human Somatic Cell and Gene Therapy", the in vitro expansion of MSCs is considered as more-than-minimal-manipulated human cellular therapy/products (HCT/Ps) [164]. Furthermore, the use of third-party MSCs must fulfill a number of parameters, including donor eligibility (communicable disease testing), quality assurance program (GMP conditions, quality control system) and distributing release criteria. All processes regarding the processing and release of MSCs must be detailed described by standard operation procedures (SOPs) documentation, to reduce at minimum the risk. All MSC therapies must be registered to the corresponded authorities, including the Food and Drug Administration (FDA), European Medicinal Agency (EMA) and Therapeutic Goods Administration (TGA) [164].

In terms of personalized medicine, more research is required, to evaluate better properties of MSCs obtained from different sources. This compromises an interesting scientific field for the development of safe and effective regenerative therapies. Existing evidence suggests that MSCs have important immunoregulatory and regenerative properties, and this potential can be used in a great number of clinical applications.

\section{Abbreviations}

aGvHD: acute Graft versus Host Disease

ALS: amyotrophic lateral sclerosis

ALSFRS: amyotrophic lateral sclerosis functional rate scale

ALSFRS-R: amyotrophic lateral sclerosis functional rate scale-revised

AT: adipose tissue

BM: bone marrow

Bregs: regulatory B cells

CCL: Chemokine (C-C motif) ligand

CD: cluster of differentiation

CDAI: Crohn's Disease Activity Index

cGvHD: chronic graft versus host disease

COVID-19: coronavirus disease-19

CPCs: cardiac progenitor cells

CXCR: C-X-C chemokine receptor 
DCs: dendritic cells

GvHD: graft versus host disease

HGF: hepatocyte growth factor

HLA: human leukocyte antigen

HSCs: hemopoietic stem cells

HSCT: hemopoietic stem cell transplantation

IDO: indoleamine 2,3 dioxygenase

IFN- $\gamma$ : interferon- $\gamma$

Ig: immunoglobulin

IL: interleukin

ISCT: International Society for Cell and Gene Therapy

mDCs: "mature" dendritic cells

MHC: major histocompatibility complex

miRs: microRNAs

MS: mutliple sclerosis

MSCs: mesenchymal stromal cells

NK: natural killer

NO: nitric oxide

PD-1: programmed death-1

PD-L1: programmed death ligand-1

PGE2: prostaglandin-E2

RNA: ribonucleic acid

SAA: severe aplastic anemia

SARS-CoV-2: severe acute respiratory syndrome coronavirus-2

SLE: systemic lupus erythematosus

TGF- $\beta 1$ : transforming growth factor- $\beta 1$

TNF- $\alpha$ : tumor necrosis factor- $\alpha$

TNTs: tunelling nanotubes

Tregs: regulatory $\mathrm{T}$ cells

UC: umbilical cord

UCB: umbilical cord blood

WJ: Wharton's Jelly

\section{Declarations}

Author contributions

PM wrote the initial draft of the manuscript. EM and TC revised the manuscript. CSG made the final approval for the manuscript.

\section{Conflicts of interest}

The authors declare that they have no conflicts of interest.

\section{Ethical approval}

Not applicable. 


\section{Consent to participate}

Not applicable.

Consent to publication

Not applicable.

Availability of data and materials

Not applicable.

\section{Funding}

Not applicable.

\section{Copyright}

(c) The Author(s) 2021.

\section{References}

1. Ullah I, Subbarao RB, Rho GJ. Human mesenchymal stem cells-current trends and future prospective. Biosci Rep. 2015;35:e00191.

2. Wei X, Yang X, Han ZP, Qu FF, Shao L, Shi YF. Mesenchymal stem cells: a new trend for cell therapy. Acta Pharmacol Sin. 2013;34:747-54.

3. Charbord P. Bone marrow mesenchymal stem cells: historical overview and concepts. Hum Gene Ther. 2010;21:1045-56.

4. Berebichez-Fridman R, Montero-Olvera PR. Sources and clinical applications of mesenchymal stem cells: state-of-the-art review. Sultan Qaboos Univ Med J. 2018;18:e264-77.

5. Hass R, Kasper C, Böhm S, Jacobs R. Different populations and sources of human mesenchymal stem cells (MSC): A comparison of adult and neonatal tissue-derived MSC. Cell Commun Signal. 2011;9:12.

6. Via AG, Frizziero A, Oliva F. Biological properties of mesenchymal stem cells from different sources. Muscles Ligaments Tendons J. 2012;2:154-62.

7. Chen JY, Mou XZ, Du XC, Xiang C. Comparative analysis of biological characteristics of adult mesenchymal stem cells with different tissue origins. Asian Pac J Trop Med. 2015;8:739-46.

8. Stewart MC, Stewart AA. Mesenchymal stem cells: characteristics, sources, and mechanisms of action. Vet Clin North Am Equine Pract. 2011;27:243-61.

9. Dominici M, Le Blanc K, Mueller I, Slaper-Cortenbach I, Marini F, Krause D, et al. Minimal criteria for defining multipotent mesenchymal stromal cells. The International Society for Cellular Therapy position statement. Cytotherapy. 2006;8:315-7.

10. Viswanathan S, Shi Y, Galipeau J, Krampera M, Leblanc K, Martin I, et al. Mesenchymal stem versus stromal cells: International Society for Cell \& Gene Therapy (ISCT®) Mesenchymal Stromal Cell committee position statement on nomenclature. Cytotherapy. 2019;21:1019-24.

11. Sipp D, Robey PG, Turner L. Clear up this stem-cell mess. Nature. 2018;561:455-457.

12. Caplan AI. Mesenchymal stem cells: time to change the name! Stem Cells Transl Med. 2017;6:1445-51.

13. Bianco P, Robey PG, Simmons PJ. Mesenchymal stem cells: revisiting history, concepts, and assays. Cell Stem Cell. 2008;2:313-9.

14. Charbord P. Bone marrow mesenchymal stem cells: historical overview and concepts. Hum Gene Ther. 2010;21:1045-56.

15. Wexler SA, Donaldson C, Denning-Kendall P, Rice C, Bradley B, Hows JM. Adult bone marrow is a rich source of human mesenchymal 'stem' cells but umbilical cord and mobilized adult blood are not. Br J Haematol. 2003;12:368-74. 
16. Baer PC, Geiger H. Adipose-derived mesenchymal stromal/stem cells: tissue localization, characterization and heterogeneity. Stem Cells Int. 2012;2012:812693.

17. Elahi KC, Klein G, Avci-Adali M, Sievert KD, MacNeil S, Aicher WK. Human mesenchymal stromal cells from different sources diverge in their expression of cell surface proteins and display distinct differentiation patterns. Stem Cells Int. 2016;2016:5646384.

18. Weiss ARR, Dahlke MH. Immunomodulation by mesenchymal stem cells (MSCs): mechanisms of action of living, apoptotic, and dead MSCs. Front Immunol. 2019;10:1191.

19. Ryan JM, Barry FP, Murphy JM, Mahon BP. Mesenchymal stem cells avoid allogeneic rejection. J Inflamm (Lond). 2005;2:8.

20. Zhao QJ, Ren HY, Han ZC. Mesenchymal stem cells: immunomodulatory capability and clinical potential in immune diseases. J Cell Immunother. 2016;2:3-20.

21. Harrell CR, Jovicic N, Djonov V, Arsenijevic N, Volarevic V. Mesenchymal stem cell-derived exosomes and other extracellular vesicles as new remedies in the therapy of inflammatory diseases. Cells. 2019;8:1605.

22. Seo Y, Kang MJ, Kim HS. Strategies to potentiate paracrine therapeutic efficacy of mesenchymal stem cells in inflammatory diseases. Int J Mol Sci. 2021;22:3397

23. De Miguel MP, Fuentes-Julián S, Blázquez-Martínez A, Pascual CY, Aller MA, Arias J, et al. Immunosuppressive properties of mesenchymal stem cells: advances and applications. Curr Mol Med. 2012;12:574-91.

24. Jiang W, Xu J. Immune modulation by mesenchymal stem cells. Cell Prolif. 2020;53:e12712.

25. Rees AJ. Monocyte and macrophage biology: an overview. Semin Nephrol. 2010;30:216-33.

26. Auffray C, Sieweke MH, Geissmann F. Blood monocytes: development, heterogeneity, and relationship with dendritic cells. Annu Rev Immunol. 2009;27:669-92.

27. Chen $\mathrm{L}$, Tredget EE, Wu PY, Wu Y. Paracrine factors of mesenchymal stem cells recruit macrophages and endothelial lineage cells and enhance wound healing. PLoS One. 2008;3:e1886.

28. Chen PM, Liu KJ, Hsu PJ, Wei CF, Bai CH, Ho LJ, et al. Induction of immunomodulatory monocytes by human mesenchymal stem cell-derived hepatocyte growth factor through ERK1/2. J Leukoc Biol. 2014;96:295-303.

29. Min H, Xu L, Parrott R, Overall CC, Lillich M, Rabjohns EM, et al. Mesenchymal stromal cells reprogram monocytes and macrophages with processing bodies. Stem Cells. 2021;39:115-28.

30. Gao S, Mao F, Zhang B, Zhang L, Zhang X, Wang M, et al. Mouse bone marrow-derived mesenchymal stem cells induce macrophage M2 polarization through the nuclear factor- $\mathrm{\kappa B}$ and signal transducer and activator of transcription 3 pathways. Exp Biol Med (Maywood). 2014;239:366-75.

31. Zhang QZ, Su WR, Shi SH, Wilder-Smith P, Xiang AP, Wong A, et al. Human gingiva-derived mesenchymal stem cells elicit polarization of $\mathrm{m} 2$ macrophages and enhance cutaneous wound healing. Stem Cells. 2010;28:1856-68.

32. Mallis P, Boulari D, Michalopoulos E, Dinou A, Spyropoulou-Vlachou M, Stavropoulos-Giokas C. Evaluation of HLA-G expression in multipotent mesenchymal stromal cells derived from vitrified Wharton's Jelly tissue. Bioengineering (Basel). 2018;5:95.

33. Bernardo ME, Fibbe WE. Mesenchymal stromal cells: sensors and switchers of inflammation. Cell Stem Cell. 2013;13:392-402.

34. Yagi H, Soto-Gutierrez A, Parekkadan B, Kitagawa Y, Tompkins RG, Kobayashi N, et al. Mesenchymal stem cells: Mechanisms of immunomodulation and homing. Cell Transplant. 2010;19:667-79.

35. Németh K, Leelahavanichkul A, Yuen PS, Mayer B, Parmelee A, Doi K, et al. Bone marrow stromal cells attenuate sepsis via prostaglandin E(2)-dependent reprogramming of host macrophages to increase their interleukin-10 production. Nat Med. 2009;15:42-9. 
36. Shapouri-Moghaddam A, Mohammadian S, Vazini H, Taghadosi M, Esmaeili SA, Mardani F, et al. Macrophage plasticity, polarization, and function in health and disease. J Cell Physiol. 2018;233:6425-40.

37. Bernardo ME, Fibbe WE. Mesenchymal stromal cells: sensors and switchers of inflammation. Cell Stem Cell. 2013;13:392-402.

38. Gur-Wahnon D, Borovsky Z, Beyth S, Liebergall M, Rachmilewitz J. Contact-dependent induction of regulatory antigen-presenting cells by human mesenchymal stem cells is mediated via STAT3 signaling. Exp Hematol. 2007;35:426-33.

39. Patente TA, Pinho MP, Oliveira AA, Evangelista GCM, Bergami-Santos PC, Barbuto JAM. Human dendritic cells: their heterogeneity and clinical application potential in cancer immunotherapy. Front Immunol. 2019;9:3176.

40. Mellman I, Steinman RM. Dendritic cells: specialized and regulated antigen processing machines. Cell. 2001;106:255-8.

41. Lu Z, Chang W, Meng S, Xu X, Xie J, Guo F, et al. Mesenchymal stem cells induce dendritic cell immune tolerance via paracrine hepatocyte growth factor to alleviate acute lung injury. Stem Cell Res Ther. 2019;10:372.

42. Djouad F, Charbonnier LM, Bouffi C, Louis-Plence P, Bony C, Apparailly F, et al. Mesenchymal stem cells inhibit the differentiation of dendritic cells through an interleukin-6-dependent mechanism. Stem Cells. 2007;25:2025-32.

43. English K, Barry FP, Mahon BP. Murine mesenchymal stem cells suppress dendritic cell migration, maturation and antigen presentation. Immunol Lett. 2008;115:50-8.

44. Spaggiari GM, Abdelrazik H, Becchetti F, Moretta L. MSCs inhibit monocyte-derived DC maturation and function by selectively interfering with the generation of immature DCs: central role of MSC-derived prostaglandin E2. Blood. 2009;113:6576-83.

45. Liu Y, Yin Z, Zhang R, Yan K, Chen L, Chen F, et al. MSCs inhibit bone marrow-derived DC maturation and function through the release of TSG-6. Biochem Biophys Res Commun. 2014;450:1409-15.

46. Scalavino V, Liso M, Serino G. Role of microRNAs in the regulation of dendritic cell generation and function. Int J Mol Sci. 2020;21:1319.

47. Chen W, Huang Y, Han J, Yu L, Li Y, Lu Z, et al. Immunomodulatory effects of mesenchymal stromal cells-derived exosome. Immunol Res. 2016;64:831-40.

48. Martin-Rufino JD, Espinosa-Lara N, Osugui L, Sanchez-Guijo F. Targeting the immune system with mesenchymal stromal cell-derived extracellular vesicles: what is the cargo's mechanism of action? Front Bioeng Biotechnol. 2019;7:308.

49. Reis M, Mavin E, Nicholson L, Green K, Dickinson AM, Wang XN. Mesenchymal stromal cell-derived extracellular vesicles attenuate dendritic cell maturation and function. Front Immunol. 2018;9:2538.

50. Favaro E, Carpanetto A, Caorsi C, Giovarelli M, Angelini C, Cavallo-Perin P, et al. Human mesenchymal stem cells and derived extracellular vesicles induce regulatory dendritic cells in type 1 diabetic patients. Diabetologia. 2016;59:325-33.

51. Vivier E, Tomasello E, Baratin M, Walzer T, Ugolini S. Functions of natural killer cells. Nat Immunol. 2008;9:503-10.

52. Biassoni R. Natural killer cell receptors. Adv Exp Med Biol. 2008;640:35-52

53. Finton KA, Strong RK. Structural insights into activation of antiviral NK cell responses. Immunol Rev. 2012;250:239-57.

54. Casado JG, Tarazona R, Sanchez-Margallo FM. NK and MSCs crosstalk: the sense of immunomodulation and their sensitivity. Stem Cell Rev Rep. 2013;9:184-9. 
55. Najar M, Fayyad-Kazan M, Meuleman N, Bron D, Fayyad-Kazan H, Lagneaux L. Mesenchymal stromal cells of the bone marrow and natural killer cells: cell interactions and cross modulation. J Cell Commun Signal. 2018;12:673-88.

56. Sangiorgi B, Panepucci RA. Modulation of immunoregulatory properties of mesenchymal stromal cells by Toll-like receptors: potential applications on GVHD. Stem Cells Int. 2016;2016:9434250.

57. Holt D, Ma X, Kundu N, Fulton A. Prostaglandin $\mathrm{E}_{2}\left(\mathrm{PGE}_{2}\right)$ suppresses natural killer cell function primarily through the PGE ${ }_{2}$ receptor EP4. Cancer Immunol Immunother. 2011;60:1577-86.

58. Najar M, Fayyad-Kazan M, Meuleman N, Bron D, Fayyad-Kazan H, Lagneaux L. Immunological impact of Wharton's Jelly mesenchymal stromal cells and natural killer cell co-culture. Mol Cell Biochem. 2018;447:111-24.

59. Hughes PD, Cohney SJ. Modifiers of complement activation for prevention of antibody-mediated injury to allografts. Curr Opin Organ Transplant. 2011;16:425-33.

60. Li Y, Lin F. Mesenchymal stem cells are injured by complement after their contact with serum. Blood. 2012;120:3436-43.

61. Janssen BJ, Huizinga EG, Raaijmakers HC, Roos A, Daha MR, Nilsson-Ekdahl K, et al. Structures of complement component C3 provide insights into the function and evolution of immunity. Nature. 2005;437:505-11.

62. Le Blanc K, Mougiakakos D. Multipotent mesenchymal stromal cells and the innate immune system. Nat Rev Immunol. 2012;12:383-96.

63. Moll G, Jitschin R, von Bahr L, Rasmusson-Duprez I, Sundberg B, Lönnies L, et al. Mesenchymal stromal cells engage complement and complement receptor bearing innate effector cells to modulate immune responses. PLoS One. 2011;6:e21703.

64. Tu Z, Li Q, Bu H, Lin F. Mesenchymal stem cells inhibit complement activation by secreting factor H. Stem Cells Dev. 2010;19:1803-9.

65. Haddad R, Saldanha-Araujo F. Mechanisms of T-cell immunosuppression by mesenchymal stromal cells: what do we know so far? Biomed Res Int. 2014;2014:216806.

66. Davies LC, Heldring N, Kadri N, Le Blanc K. Mesenchymal stromal cell secretion of programmed death-1 ligands regulates T cell mediated immunosuppression. Stem Cells. 2017;35:766-76.

67. Sreeramkumar V, Fresno M, Cuesta N. Prostaglandin E2 and T cells: friends or foes? Immunol Cell Biol. 2012;90:579-86.

68. Ricciotti E, FitzGerald GA. Prostaglandins and inflammation. Arterioscler Thromb Vasc Biol. 2011;31: 986-1000.

69. Ryan JM, Barry F, Murphy JM, Mahon BP. Interferon-gamma does not break, but promotes the immunosuppressive capacity of adult human mesenchymal stem cells. Clin Exp Immunol. 2007;149: 353-63.

70. Ren G, Zhang L, Zhao X, Xu G, Zhang Y, Roberts AI, et al. Mesenchymal stem cell-mediated immunosuppression occurs via concerted action of chemokines and nitric oxide. Cell Stem Cell. 2008;2:141-50.

71. Wang L, Zhao Y, Shi S. Interplay between mesenchymal stem cells and lymphocytes: implications for immunotherapy and tissue regeneration. J Dent Res. 2012;91:1003-10.

72. Franquesa M, Hoogduijn MJ, Bestard O, Grinyó JM. Immunomodulatory effect of mesenchymal stem cells on B cells. Front Immunol. 2012;3:212.

73. Fan L, Hu C, Chen J, Cen P, Wang J, Li L. Interaction between mesenchymal stem cells and B-cells. Int J Mol Sci. 2016;17:650.

74. Asari S, Itakura S, Ferreri K, Liu CP, Kuroda Y, Kandeel F, et al. Mesenchymal stem cells suppress B-cell terminal differentiation. Exp Hematol. 2009;37:604-15. 
75. Naji A, Rouas-Freiss N, Durrbach A, Carosella ED, Sensébé L, Deschaseaux F. Concise review: combining human leukocyte antigen $\mathrm{G}$ and mesenchymal stem cells for immunosuppressant biotherapy. Stem Cells. 2013;31:2296-303.

76. Gao F, Chiu SM, Motan DA, Zhang Z, Chen L, Ji HL, et al. Mesenchymal stem cells and immunomodulation: current status and future prospects. Cell Death Dis. 2016;7:e2062.

77. Gieseke F, Böhringer J, Bussolari R, Dominici M, Handgretinger R, Müller I. Human multipotent mesenchymal stromal cells use galectin-1 to inhibit immune effector cells. Blood. 2010;116:3770-9.

78. Machado Cde V, Telles PD, Nascimento IL. Immunological characteristics of mesenchymal stem cells. Rev Bras Hematol Hemoter. 2013;35:62-7.

79. Wang LT, Ting CH, Yen ML, Liu KJ, Sytwu HK, Wu KK, et al. Human mesenchymal stem cells (MSCs) for treatment towards immune- and inflammation-mediated diseases: review of current clinical trials. J Biomed Sci. 2016;23:76.

80. Battiwalla M, Hematti P. Mesenchymal stem cells in hematopoietic stem cell transplantation. Cytotherapy. 2009;11:503-15.

81. Koç ON, Peters C, Aubourg P, Raghavan S, Dyhouse S, DeGasperi R, et al. Bone marrow-derived mesenchymal stem cells remain host-derived despite successful hematopoietic engraftment after allogeneic transplantation in patients with lysosomal and peroxisomal storage diseases. Exp Hematol. 1999;27:1675-81.

82. Lazarus HM, Koc ON, Devine SM, Curtin P, Maziarz RT, Holland HK, et al. Cotransplantation of HLAidentical sibling culture-expanded mesenchymal stem cells and hematopoietic stem cells in hematologic malignancy patients. Biol Blood Marrow Transplant. 2005;11:389-98.

83. Koç ON, Gerson SL, Cooper BW, Dyhouse SM, Haynesworth SE, Caplan AI, et al. Rapid hematopoietic recovery after coinfusion of autologous-blood stem cells and culture-expanded marrow mesenchymal stem cells in advanced breast cancer patients receiving high-dose chemotherapy. J Clin Oncol. 2000;18:307-16.

84. Kallekleiv M, Larun L, Bruserud Ø, Hatfield KJ. Co-transplantation of multipotent mesenchymal stromal cells in allogeneic hematopoietic stem cell transplantation: a systematic review and meta-analysis. Cytotherapy. 2016;18:172-85.

85. Ball LM, Bernardo ME, Roelofs H, Lankester A, Cometa A, Egeler RM, et al. Cotransplantation of ex vivo expanded mesenchymal stem cells accelerates lymphocyte recovery and may reduce the risk of graft failure in haploidentical hematopoietic stem-cell transplantation. Blood. 2007;110:2764-7.

86. Macmillan ML, Blazar BR, DeFor TE, Wagner JE. Transplantation of ex-vivo culture-expanded parental haploidentical mesenchymal stem cells to promote engraftment in pediatric recipients of unrelated donor umbilical cord blood: results of a phase I-II clinical trial. Bone Marrow Transplant. 2009;43: 447-54.

87. Le Blanc K, Samuelsson H, Gustafsson B, Remberger M, Sundberg B, Arvidson J, et al. Transplantation of mesenchymal stem cells to enhance engraftment of hematopoietic stem cells. Leukemia. 2007;21: 1733-8.

88. Karp JM, Leng Teo GS. Mesenchymal stem cell homing: the devil is in the details. Cell Stem Cell. 2009;4:206-16.

89. Mäkelä T, Takalo R, Arvola O, Haapanen H, Yannopoulos F, Blanco R, et al. Safety and biodistribution study of bone marrow-derived mesenchymal stromal cells and mononuclear cells and the impact of the administration route in an intact porcine model. Cytotherapy. 2015;17:392-402.

90. von Bahr L, Batsis I, Moll G, Hägg M, Szakos A, Sundberg B, et al. Analysis of tissues following mesenchymal stromal cell therapy in humans indicates limited long-term engraftment and no ectopic tissue formation. Stem Cells. 2012;30:1575-8. 
91. Iacobaeus E, Kadri N, Lefsihane K, Boberg E, Gavin C, Törnqvist Andrén A, et al. Short and long term clinical and immunologic follow up after bone marrow mesenchymal stromal cell therapy in progressive multiple sclerosis-A phase I study. J Clin Med. 2019;8:2102.

92. Cheung TS, Bertolino GM, Giacomini C, Bornhäuser M, Dazzi F, Galleu A. Mesenchymal stromal cells for graft versus host disease: mechanism-based biomarkers. Front Immunol. 2020;11:1338.

93. Funke VA, Moreira MC, Vigorito AC. Acute and chronic Graft-versus-host disease after hematopoietic stem cell transplantation. Rev Assoc Med Bras. 2016;62 Suppl 1:44-50.

94. Blazar BR, Murphy WJ, Abedi M. Advances in graft-versus-host disease biology and therapy. Nat Rev Immunol. 2012;12:443-58.

95. Zeiser R, Blazar BR. Acute graft-versus-host disease-biologic process, prevention, and therapy. N Engl J Med. 2017;377:2167-79.

96. Choi SW, Levine JE, Ferrara JL. Pathogenesis and management of graft-versus-host disease. Immunol Allergy Clin North Am. 2010;30:75-101.

97. Hill L, Alousi A, Kebriaei P, Mehta R, Rezvani K, Shpall E. New and emerging therapies for acute and chronic graft versus host disease. Ther Adv Hematol. 2018;9:21-46.

98. Bader P, Kuçi Z, Bakhtiar S, Basu O, Bug G, Dennis M, et al. Effective treatment of steroid and therapyrefractory acute graft-versus host disease with a novel mesenchymal stromal cell product (MSC-FFM). Bone Marrow Transplant. 2018;53:852-62.

99. Simonetta F, Alvarez M, Negrin RS. Natural killer cells in graft-versus-host-disease after allogeneic hematopoietic cell transplantation. Front Immunol. 2017;8:465.

100. Pasquini MC. Impact of graft-versus-host disease on survival. Best Pract Res Clin Haematol. 2008;21: 193-204.

101. Kuba A, Raida L. Graft versus host disease: from basic pathogenic principles to DNA damage response and cellular senescence. Mediators Inflamm. 2018;2018:9451950.

102. Elgaz S, Kuçi Z, Kuçi S, Bönig H, Bader P. Clinical use of mesenchymal stromal cells in the treatment of acute graft-versus-host disease. Transfus Med Hemother. 2019;46:27-34.

103. Le Blanc K, Rasmusson I, Sundberg B, Götherström C, Hassan M, Uzunel M, et al. Treatment of severe acute graft-versus-host disease with third party haploidentical mesenchymal stem cells. Lancet. 2004;363:1439-41.

104. Ringden O, Baygan A, Remberger M, Gustafsson B, Winiarski J, Khoein B, et al. Placenta-derived decidua stromal cells for treatment of severe acute graft-versus-host disease. Stem Cells Transl Med. 2018; 7:325-31.

105. Le Blanc K, Frassoni F, Ball L, Locatelli F, Roelofs H, Lewis I, et al. Developmental Committee of the European Group for Blood and Marrow Transplantation. Mesenchymal stem cells for treatment of steroid-resistant severe, acute graft-versus-host disease: a phase II study. Lancet. 2008;371:1579-86.

106. Dotoli GM, De Santis GC, Orellana MD, de Lima Prata K, Caruso SR, Fernandes TR, et al. Mesenchymal stromal cell infusion to treat steroid-refractory acute GvHD III/IV after hematopoietic stem cell transplantation. Bone Marrow Transplant. 2017;52:859-62.

107. von Dalowski F, Kramer M, Wermke M, Wehner R, Röllig C, Alakel N, et al. Mesenchymal stromal cells for treatment of acute steroid-refractory graft versus host disease: clinical responses and long-term outcome. Stem Cells. 2016;34:357-66.

108. Liu Z, Zhang Y, Xiao H, Yao Z, Zhang H, Liu Q, et al. Cotransplantation of bone marrow-derived mesenchymal stem cells in haploidentical hematopoietic stem cell transplantation in patients with severe aplastic anemia: an interim summary for a multicenter phase II trial results. Bone Marrow Transplant. 2017;52:704-10.

109. Angum F, Khan T, Kaler J, Siddiqui L, Hussain A. The prevalence of autoimmune disorders in women: a narrative review. Cureus. 2020;12:e8094. 
110. Figueroa FE, Carrión F, Villanueva S, Khoury M. Mesenchymal stem cell treatment for autoimmune diseases: a critical review. Biol Res. 2012;45:269-77.

111. Rad F, Ghorbani M, Mohammadi Roushandeh A, Habibi Roudkenar M. Mesenchymal stem cell-based therapy for autoimmune diseases: emerging roles of extracellular vesicles. Mol Biol Rep. 2019;46: 1533-49.

112. Tyndall A, Houssiau FA. Mesenchymal stem cells in the treatment of autoimmune diseases. Ann Rheum Dis. 2010;69:1413-4.

113. Pistoia V, Raffaghello L. Mesenchymal stromal cells and autoimmunity. Int Immunol. 2017;29:49-58.

114. Rees F, Doherty M, Grainge MJ, Lanyon P, Zhang W. The worldwide incidence and prevalence of systemic lupus erythematosus: a systematic review of epidemiological studies. Rheumatology (Oxford). 2017;56:1945-61.

115. Perl A. Systems biology of lupus: mapping the impact of genomic and environmental factors on gene expression signatures, cellular signaling, metabolic pathways, hormonal and cytokine imbalance, and selecting targets for treatment. Autoimmunity. 2010;43:32-47.

116. Feng X, Li R, Huang J, Zhang H, Zhu L, Hua B, et al. Olf1/EBF associated zinc finger protein interfered with antinuclear antibody production in patients with systemic lupus erythematosus. Arthritis Res Ther. 2010;12:R59.

117. Feng X, Che N, Liu Y, Chen H, Wang D, Li X, et al. Restored immunosuppressive effect of mesenchymal stem cells on B cells after olfactory 1/early B cell factor-associated zinc-finger protein down-regulation in patients with systemic lupus erythematosus. Arthritis Rheumatol. 2014;66:3413-23.

118. Alessandri C, Barbati C, Vacirca D, Piscopo P, Confaloni A, Sanchez M, et al. T lymphocytes from patients with systemic lupus erythematosus are resistant to induction of autophagy. FASEB J. 2012;26:4722-32.

119. Wang F, Tasset I, Cuervo AM, Muller S. In vivo remodeling of altered autophagy-lysosomal pathway by a phosphopeptide in lupus. Cells. 2020;9:2328.

120. Chen J, Wang $Q$ Feng X, Zhang Z, Geng L, Xu T, et al. Umbilical cord-derived mesenchymal stem cells suppress autophagy of $T$ cells in patients with systemic lupus erythematosus via transfer of mitochondria. Stem Cells Int. 2016;2016:4062789.

121. Liang J, Zhang H, Hua B, Wang H, Lu L, Shi S, et al. Allogenic mesenchymal stem cells transplantation in refractory systemic lupus erythematosus: a pilot clinical study. Ann Rheum Dis. 2010;69:1423-9.

122. Boyapati R, Satsangi J, Ho GT. Pathogenesis of Crohn's disease. F1000Prime Rep. 2015;7:44.

123. Marks DJ, Rahman FZ, Sewell GW, Segal AW. Crohn's disease: an immune deficiency state. Clin Rev Allergy Immunol. 2010;38:20-31.

124. Ruffolo C, Scarpa M, Bassi N. Infliximab, azathioprine, or combination therapy for Crohn's disease. N Engl J Med. 2010;363:1086-7.

125. Dalal J, Gandy K, Domen J. Role of mesenchymal stem cell therapy in Crohn's disease. Pediatr Res. 2012;71:445-51

126. Onken J, Gallup D, Hanson J, Pandak M, Custer L. Successful outpatient treatment of refractory Crohn's disease using adult mesenchymal stem cells. American College of Gastroenterology Conference, Las Vegas, NV, Abstract 2006, 121.

127. Ciccocioppo R, Bernardo ME, Sgarella A, Maccario R, Avanzini MA, Ubezio C, et al. Autologous bone marrow-derived mesenchymal stromal cells in the treatment of fistulising Crohn's disease. Gut. 2011;60:788-98.

128. García-Olmo D, García-Arranz M, Herreros D, Pascual I, Peiro C, Rodríguez-Montes JA. A phase I clinical trial of the treatment of Crohn's fistula by adipose mesenchymal stem cell transplantation. Dis Colon Rectum. 2005;48:1416-23. 
129. Loma I, Heyman R. Multiple sclerosis: pathogenesis and treatment. Curr Neuropharmacol. 2011;9: 409-16.

130. Ghasemi N, Razavi S, Nikzad E. Multiple sclerosis: pathogenesis, symptoms, diagnoses and cell-based therapy. Cell J. 2017;19:1-10.

131. Pandit L, Murthy JM. Treatment of multiple sclerosis. Ann Indian Acad Neurol. 2011;14 Suppl 1:S65-9.

132. Kassis I, Vaknin-Dembinsky A, Karussis D. Bone marrow mesenchymal stem cells: agents of immunomodulation and neuroprotection. Curr Stem Cell Res Ther. 2011;6:63-8.

133. Karussis D. Worldwide status of clinical experimentation with stem cells in neurologic diseases. Neurology. 2012;78:1334-6.

134. Karussis D, Karageorgiou C, Vaknin-Dembinsky A, Gowda-Kurkalli B, Gomori JM, Kassis I, et al. Safety and immunological effects of mesenchymal stem cell transplantation in patients with multiple sclerosis and amyotrophic lateral sclerosis. Arch Neurol. 2010;67:1187-94.

135. Connick P, Kolappan M, Crawley C, Webber DJ, Patani R, Michell AW, et al. Autologous mesenchymal stem cells for the treatment of secondary progressive multiple sclerosis: an open-label phase 2a proof-ofconcept study. Lancet Neurol. 2012;11:150-6.

136. Gugliandolo A, Bramanti P, Mazzon E. Mesenchymal stem cells: a potential therapeutic approach for amyotrophic lateral sclerosis? Stem Cells Int. 2019;2019:3675627.

137. Nabavi SM, Arab L, Jarooghi N, Bolurieh T, Abbasi F, Mardpour S, et al. Safety, feasibility of intravenous and intrathecal injection of autologous bone marrow derived mesenchymal stromal cells in patients with amyotrophic lateral sclerosis: an open label phase I clinical trial. Cell J. 2019;20:592-8.

138. Oh KW, Moon C, Kim HY, Oh SI, Park J, Lee JH, et al. Phase I trial of repeated intrathecal autologous bone marrow-derived mesenchymal stromal cells in amyotrophic lateral sclerosis. Stem Cells Transl Med. 2015;4:590-7.

139. Petrou P, Gothelf Y, Argov Z, Gotkine M, Levy YS, Kassis I, et al. Safety and clinical effects of mesenchymal stem cells secreting neurotrophic factor transplantation in patients with amyotrophic lateral sclerosis: results of phase 1/2 and 2a clinical trials. JAMA Neurol. 2016;73:337-44.

140. Mallam E, Kemp K, Wilkins A, Rice C, Scolding N. Characterization of in vitro expanded bone marrowderived mesenchymal stem cells from patients with multiple sclerosis. Mult Scler. 2010;16:909-18.

141. Gugliandolo A, Bramanti P, Mazzon E. Mesenchymal stem cells in multiple sclerosis: recent evidence from pre-clinical to clinical studies. Int J Mol Sci. 2020;21:8662.

142. Lu H, Stratton CW, Tang YW. Outbreak of pneumonia of unknown etiology in Wuhan, China: The mystery and the miracle. J Med Virol. 2020;92:401-2.

143. Lai CC, Shih TP, Ko WC, Tang HJ, Hsueh PR. Severe acute respiratory syndrome coronavirus 2 (SARSCoV-2) and coronavirus disease-2019 (COVID-19): the epidemic and the challenges. Int J Antimicrob Agents. 2020;55:105924.

144. Coronaviridae Study Group of the International Committee on Taxonomy of Viruses. The species Severe acute respiratory syndrome-related coronavirus: classifying 2019-nCoV and naming it SARS-CoV-2. Nat Microbiol. 2020;5:536-44.

145. Awadasseid A, Wu Y, Tanaka Y, Zhang W. SARS-CoV-2 variants evolved during the early stage of the pandemic and effects of mutations on adaptation in Wuhan populations. Int J Biol Sci. 2021;17:97-106.

146. Mallis P, Michalopoulos E, Chatzistamatiou T, Stavropoulos-Giokas C. Mesenchymal stromal cells as potential immunomodulatory players in severe acute respiratory distress syndrome induced by SARSCoV-2 infection. World J Stem Cells. 2020;12:731-51.

147. Afarid M, Sanie-Jahromi F. Mesenchymal stem cells and COVID-19: cure, prevention, and vaccination. Stem Cells Int. 2021;2021:6666370. 
148. Harrell CR, Jovicic BP, Djonov V, Volarevic V. Therapeutic potential of mesenchymal stem cells and their secretome in the treatment of SARS-CoV-2-induced acute respiratory distress syndrome. Anal Cell Pathol (Amst). 2020;2020:1939768.

149. Qin H, Zhao A. Mesenchymal stem cell therapy for acute respiratory distress syndrome: from basic to clinics. Protein Cell. 2020;11:707-22.

150. Gorman E, Millar J, McAuley D, O'Kane C. Mesenchymal stromal cells for acute respiratory distress syndrome (ARDS), sepsis, and COVID-19 infection: optimizing the therapeutic potential. Expert Rev Respir Med. 2021;15:301-24.

151. Hamdan H, Hashmi SK, Lazarus H, Gale RP, Qu W, El Fakih R. Promising role for mesenchymal stromal cells in coronavirus infectious disease-19 (COVID-19)-related severe acute respiratory syndrome? Blood Rev. 2021;46:100742.

152. Leng Z, Zhu R, Hou W, Feng Y, Yang Y, Han Q, et al. Transplantation of ACE2- mesenchymal stem cells improves the outcome of patients with COVID-19 pneumonia. Aging Dis. 2020;11:216-28.

153. Chatzistamatiou TK, Papassavas AC, Michalopoulos E, Gamaloutsos C, Mallis P, Gontika I, et al. Optimizing isolation culture and freezing methods to preserve Wharton's jelly's mesenchymal stem cell (MSC) properties: an MSC banking protocol validation for the Hellenic Cord Blood Bank. Transfusion. 2014;54:3108-20.

154. Redondo J, Sarkar P, Kemp K, Heesom KJ, Wilkins A, Scolding NJ, et al. Dysregulation of mesenchymal stromal cell antioxidant responses in progressive multiple sclerosis. Stem Cells Transl Med. 2018;7: 748-58.

155. Sagar R, Walther-Jallow L, David AL, Götherström C, Westgren M. Fetal mesenchymal stromal cells: an opportunity for prenatal cellular therapy. Curr Stem Cell Rep. 2018;4:61-8.

156. Ding DC, Chou HL, Chang YH, Hung WT, Liu HW, Chu TY. Characterization of HLA-G and related immunosuppressive effects in human umbilical cord stroma-derived stem cells. Cell Transplant. 2016;25:217-28.

157. Hunt JS, Petroff MG, McIntire RH, Ober C. HLA-G and immune tolerance in pregnancy. FASEB J. 2005;19:681-93.

158. Le Blanc K, Tammik C, Rosendahl K, Zetterberg E, Ringdén O. HLA expression and immunologic properties of differentiated and undifferentiated mesenchymal stem cells. Exp Hematol. 2003;31:890-6.

159. Castro-Manrreza ME, Montesinos JJ. Immunoregulation by mesenchymal stem cells: biological aspects and clinical applications. J Immunol Res. 2015;2015:394917.

160. Lin L, Du L. The role of secreted factors in stem cells-mediated immune regulation. Cell Immunol. 2018;326:24-32.

161. van den Hoogen P, de Jager SCA, Mol EA, Schoneveld AS, Huibers MMH, Vink A, et al. Potential of mesenchymal-and cardiac progenitor cells for therapeutic targeting of B-cells and antibody responses in end-stage heart failure. PLoS One. 2019;14:e0227283.

162. Cai J, Wu J, Wang J, Li Y, Hu X, Luo S, et al. Extracellular vesicles derived from different sources of mesenchymal stem cells: therapeutic effects and translational potential. Cell Biosci. 2020:10:69.

163. Khan RS, Newsome PN. A comparison of phenotypic and functional properties of mesenchymal stromal cells and multipotent adult progenitor cells. Front Immunol. 2019:10:1952

164. Deasy BM, Anderson JE, Zelina S. Regulatory issues in the therapeutic use of stem cells. In: Andrades JA, editor. Regenerative Medicine and Tissue Engineering. London. IntechOpen. 2013. 